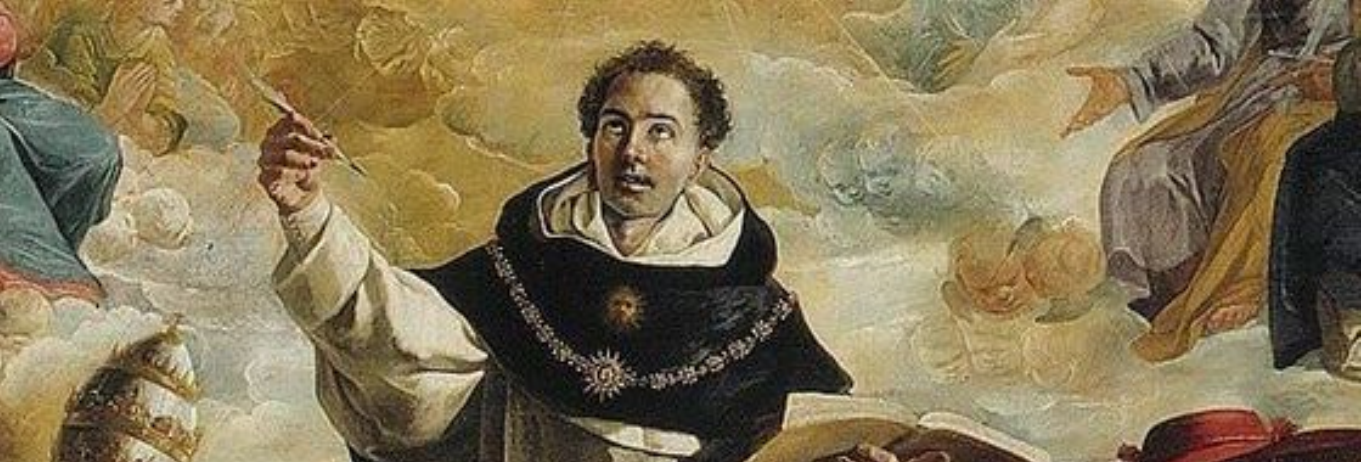

\section{La generación del Verbo eterno según Tomás de Aquino}

\section{The Generation of the Eternal Word According to Thomas Aquinas}

\section{Resumen}

El propósito de este estudio es mostrar que la vida divina ocupa la cima de la perfección vital porque es vida intelectual fecunda según Sto. Tomás de Aquino. Pero esta vida en acto fecunda también se encuentra en el sujeto intelectual finito que produce un verbo al conocer y manifestar lo que es que es. La generación divina del Verbo es fruto de la vida en acto de Dios mediante actividad inteligible que tiene como término propio la procesión del Verbo subsistente mediante generación inteligible. En virtud de la perfección de la actividad generativa del Verbo Santo Tomás sostiene en sus obras de madurez que éste es propiamente nombre personal y no meramente de la esencia.

\section{Palabras clave}

Generación, procesión, verbo, especie inteligible, gnoseología.

\section{Abstract}

The purpose of this study is to show that the divine life occupies the peak of vital perfection because it is a fruitful intellectual life, according to St. Thomas Aquinas. But this life in a fertile act is also found in the finite intellectual subject that produces a verb by knowing and manifesting what it is that is. The divine generation of the Word is the fruit of the life in the act of God through intelligible activity that has as its own term the procession of the subsistent Word through intelligible generation. By virtue of the perfection of the generative activity of the Word, Aquinas maintains in his mature works that this is properly a personal name and not merely of the essence.
\end{abstract}

\section{Keywords}

Generation, procession, verb, intelligible species, epistemology.

\section{MAURICIO ÓRDENES MORALES} Universidad San Sebastián, Chile

Licenciado en teología Pontificia Universidad Católica. Magíster en filosofía Universidad de los Andes, Chile. Profesor del Instituto de filosofía de la Universidad San Sebastián. Autor de Santo Tomás de Aquino. "Los principios de la Naturaleza", Editorial Universitaria, 2002. "La teología del Verbo según Santo Tomás en la Suma Contra Gentiles", en E. GÓMEZ (Ed), La persona: divina, angélica, humana. Actas del primer Congreso Internacional de filosofía tomista, Santiago, CET, 2014. "Conocimiento y verdad según Tomás de Aquino", Revista Chilena de Estudios Medievales, 14, 2018.

\title{
ORCID
}

Recepción de artículo: $23-11-2020$
Aceptación del artículo: $4-3-2021$

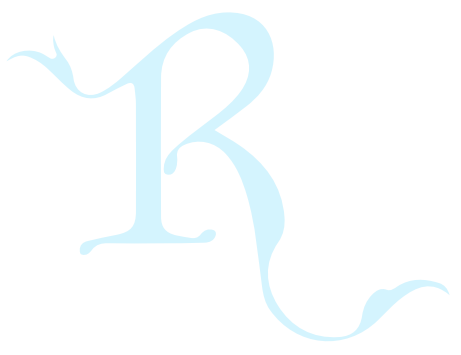


Las primeras especulaciones trinitarias de la época patrística surgen en el ámbito de autores gnósticos en los que hay elementos triádicos para expresar este misterio y culminarán en las formulaciones de los Concilios de Nicea y Constantinopla después de una ardua purificación. Era frecuente en estos autores el uso de la analogía de la luz para expresar no sólo la relación entre el Padre y el Hijo, sino de Dios con todo lo que participa de su perfección. Estos autores usarán la imagen de la luz como el substrato de lo Divino y desde ella se nombra al Unigénito y de todo el cosmos inferior e inanimado. La esencia de Dios es luz pura, luz superior, la luz sobre toda luz, suma simplicidad y de cuya simplicidad participan todos los seres inferiores ${ }^{1}$. Debemos a estos autores los primeros tanteos en la especulación del misterio más importante del cristianismo. Este esfuerzo intelectual culminará en la obra De Trinitate de San Agustín donde se desarrollará una teología de gran profundidad especulativa y de la cual el Aquinate será un fiel seguidor ${ }^{2}$. También merece destacarse el De Trinitate de San Hilario de Poitiers por su sistematización de la doctrina católica en contra de los arrianos. Pero sin duda alguna que todo este itinerario intelectual culminará en la síntesis escolástica de Tomás de Aquino, que no sólo asumirá toda la doctrina patrística de los grandes teólogos de la Trinidad, sino que elaborará una síntesis personal desde sus propias categorías filosóficas. No obstante, el pensamiento del Aquinate también tuvo su propia maduración, así, por ejemplo, en obras de juventud concibió que el Verbo no era nombre personal, sino también nombre de esencia apropiado a la persona del Hijo, tesis que abandonará en la Suma de Teología; de igual manera, también afirmó que la generación del Verbo no era exclusivamente por emanación intelectual, sino que podía entenderse a la vez tanto como una generación intelectual y una procesión natural no personal. Dos tesis que abandonará definitivamente en su obra más perfecta, la Suma de Teología, donde afirmó sin vacilación que Verbo es nombre personal y que la generación del Verbo es por emanación intelectual. Ahora bien, este desarrollo del pensamiento del Aquinate responde a su interés de profundizar en la Revelación del nombre de Verbo que encuentra en la Escritura. Pues, para nuestro autor y sus contemporáneos no era fácil de armonizar el acto de entender de Dios uno con el acto por el cual se profiere un Verbo, que es Imagen de quien procede. Por ello, Tomás, siempre fiel a la Escritura y los concilios ecuménicos, no duda en rectificar su posición teológica juvenil para mantenerse fiel a la dogmática católica.
En este estudio expondremos que la vida divina no sólo es vida plena del intelecto sino también la máxima noción concebible del supremo ente $^{3}$, en segundo lugar, mostraremos la especificidad y naturaleza de la generación divina como actividad intelectual fecunda por modo de semejanza que emana como acto de acto, y en último término la naturaleza personal del Verbo divino generado por la acción del intelecto en acto como actividad fecunda ${ }^{4}$. En todo momento tendremos presente la ontología del conocimiento tal como la ha expuesto Canals Vidal, que ha rerdescubierto que el verbo concebido por el intelecto es fruto de la actividad vital fecunda del intelecto en cuanto tal. ${ }^{5}$

\section{LA VIDA DIVINA}

Que el punto de partida de la especulación teológica del Aquinate es la Revelación de la existencia en Dios de procesiones no le impide avanzar en el esfuerzo de tratar de comprender cómo puede ser profundizada esta verdad después de dicha Revelación. La Sagrada Escritura es el canon de su especulación teológica, y por eso escribe: "La Sagrada Escritura, en las cosas divinas, usa nombres que pertenecen a la procesión" ${ }^{6}$. La Escritura enseña que en Dios hay procesiones y forma parte de la tarea del teólogo usar razones para entrar en la comprensión del misterio, no en su demostración 7 . El cristiano debe poner su razón al servicio de la comprensión del misterio revelado, pues la misma Revelación divina se hizo según un cierto orden "de tal modo que paulatinamente de lo imperfecto se llegue a lo perfecto"8. Y ya que la Revelación divina se ha hecho en conformidad con la constitución humana que conoce las esencias de las cosas a partir de los datos de los sentidos es posible seguir un proceso analógico ascendente para llegar a la verdad inteligible de la generación divina. De este modo, nos remontaremos en la especulación racional desde lo más conocido para nosotros a lo más conocido en si $^{9}$. "Así pues primeramente se le revelan al hombre estas cosas, de manera que no sean entendidas, sino creídas, dando fe a lo que ha oído; porque el entendimiento humano, según el estado presente por el cual está relacionado con lo sensible no puede elevarse para intuir lo que excede a la proporción de los sentidos" ${ }^{10}$. Por ello, el hombre debe elevarse a lo inmaterial desde lo material para llegar a un cierto e imperfecto conocimiento que excede la capacidad de la razón, sin embargo, es un conocimiento verdaderamente manifestativo de lo que es ${ }^{11}$. Por esta condición hilemórfica del hombre es necesario que

\section{Cf. A. ORBE 1958, 3-57}

Cf. S. Th. I, q. 32, a. 1, ad 2. Cf. Cf. ARIAS REYERO 1987, pp. 33-56; PIERANTONI 2011, pp.197-210; MUÑOZ VEGA 1981. HORN. 2012.

Lo que no significa que el constituitivo formal de la divinidad sea la intelectualidad.

4. Para el Aquinate, el conocimiento de las procesiones intratrinitarias es necesario, a su vez, para pensar rectamente en la libertad del acto creador. Cf.

S. Th. q. 32, a. 1, ad 3.

5. Cf. CANALS VIDAL 1987.

6. S. Th. I, q. 27, a.1.

7. La posición del Aquinate es mostrar que hay razones congruentes con la Revelación, pero no prueba el dato revelado desde un sistema filosófico. Sobre la infundada acusación de racionalismo de la postura de Tomàs de Aquino en virtud de la cual nuestro autor pretendería probar que en Dios existe un verbo, ver IZQUIERDO 1982/2, pp. 569-574.

8. SCG. IV. 1, n. 8 .

9. Entendiendo que lo más conocido para nosotros en lo que posee menos entidad en sí, y lo más conocido en sí, pero no para nosotros es lo que posee mayor entidad ontológica. Nuestro entendimiento denomina las cosas divinas no como son en sí mismas, sino conforme al modo de ser que tienen en las criaturas. Cf. S. Th. I, q. 39, a. 2; I, q. 32, a. 1.

10. SCG. IV, 1, n. 8; Cf. S. Th. I, q. 39, a. 1

11. Por ello, para el Aquinate inspirado en la metafísica del espíritu de San Agustín, la inmaterialidad del alma es el punto de partida para conocer la inmaterialidad de Dios. Cf. S. Th. I, q. 88, a. 1, ad 2. 
se remonte a la perfección divina desde las perfecciones creadas que son aquello que le es más manifiesto según su condición corporal. El trabajo teológico, que es una obra racional, y cuyo punto de partida es aquello que nos es más conocido para nosotros dada nuestra condición hilemórfica, culmina en la comprensión del significado de la verdad que ha sido recibida como revelada.

El Aquinate ha leído en Escritura que Dios es vida, ${ }^{12 " e n ~ e l l a ~ e s t a b a ~ l a ~}$ vida" , y también conoce que el Filósofo asigna la perfección de la vida intelectual a Dios ${ }^{13}$. Por ello, no duda en comprender a Dios como el viviente supremo. "En Dios su entender es su vida y su esencia"14. Ahora bien, la vida para el Aquinate es una perfección de ciertos seres que se mueven a sí mismos y cuyo ámbito de estudio primeramente es el de la filosofía de la naturaleza. En esta primera perspectiva aristotélica el viviente es reconocido como un ente cuyo principio de movimiento le es intrínseco ${ }^{15}$. Sin embargo, tanto Aristóteles como el Aquinate ponen la perfección de la vida en un nivel que no sólo supera el de las perfecciones categoriales, sino de las trascendentales. Pues para Aristóteles el vivir es el mismo ser del viviente ${ }^{16}$, de tal modo que la actividad vital puede ser comprendida desde la perspectiva de las propias operaciones inmanentes del viviente. Para Sto. Tomás este modo de ser que hace que el viviente sea él mismo principio y término de sus operaciones no sólo lo conduce a la comprensión de la perfección de la vida en niveles de diferentes grados de perfección de operaciones que emanan de su ser, sino también a entender que la vida es una perfección que responde a un acto más originario, íntimo y radical como es el acto de ser. Si las operaciones vitales no emanaran del núcleo más íntimo del viviente que está constituido por su ser no podríamos entender el conocimiento como una forma más perfecta de automovimiento y a través de cuya perfección se expresa su ser. Para Sto. Tomás la perfección de la vida está arraigada en la perfección del ser, el acto de todos los actos y la perfección de todas las perfecciones, pues ninguna perfección adviene al ente sino es por el acto de ser. Por ello, el hombre como cognoscente racional participa más de la perfección del ser, de tal modo que, si un ente no es capaz de las operaciones vitales de conocer y amar es por la imperfección con la que participa del acto de ser. Si el conocimiento es perfección vital de un cognoscente es porque el ser cognoscente es más perfecto que un ser que solamente vive. "Pues, aunque el ente no incluya en sí el ser viviente y ser sabio porque no es necesario que todo aquel que participe del ser lo participe según todo el modo de ser, sin embargo, el mismo ser de Dios incluye en sí la vida y la sabiduría porque ninguna de las perfecciones del ser puede faltar a aquel que es el mismo ser subsistente" ${ }^{17}$. Porque no se podría significar ninguna perfección en acto si no fuera por la perfección del ser, acto de todos los actos. Ya que, "la perfección de cualquier cosa es proporcionada a su ser, pues ninguna nobleza le vendría al hombre por su sabiduría si por ella no fuese sabio... Así pues, según el modo por el cual las cosas tienen ser es su modo de nobleza"18. Desde la perspectiva del ser como acto se entiende que el cognoscente racional posee una plenitud ontológica superior por una participación en el ser de un modo más perfecto. "Precisamente porque el vivir se refiere al ser, apuntando ya inmediatamente al sujeto viviente como principio de operaciones, y porque el obrar sigue al ser y no a la inversa, concebimos más perfectamente el viviente desde su participación en el ser" ${ }^{\prime 19}$. Por ello, enseña el Aquinate que si en Dios se da el supremo grado de vida también se dará en plenitud la vida inteligente. Para el Aquinate Dios es el ser que posee la vida en grado máximo porque en él el entender se identifica con su ser. Por ello, el Aquinate se pregunta si el nombre vida significa la operación misma del viviente y responde que más bien significa el ser mismo del viviente. "Y según esto vivir no es otra cosa que ser en tal naturaleza; y vida significa lo mismo, pero en abstracto igual que el nombre carrera significa el mismo correr en abstracto. Por ello ser vivo no es predicado accidental, sino substancial" ${ }^{20}$. Como la vida es acto, explica, Sto. Tomás, que el nombre de vida se tomó en un principio para nombrar el viviente por los efectos externos, sin embargo, propiamente significa el mismo ser o substancia a la que por naturaleza le conviene ser principio de sus acciones y que de ningún modo es impulsado por otro desde fuera ${ }^{21}$. Y esta mayor identificación entre el ser y su operación se da en Dios donde su vida es su mismo entender e inteligir.

12. Juan 1, 4; 14, 6 .

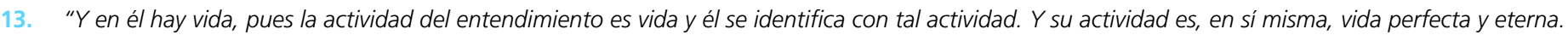
Afirmamos que Dios es un viviente eterno y perfecto. Así pues, a Dios corresponde vivir una vida perfecta y eterna. Esto es, pues, Dios". ARISTÓTELES. Metafísica, XII, 7, 1072b 25-29.

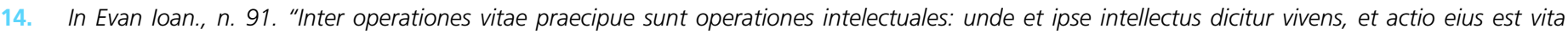
quaedam. In Deo autem idem est intelligere et intelectus: unde manifestum est quod Filius. Qui est Verbum intellectus Patris, est vita sua". In Evan loan. n. 1869

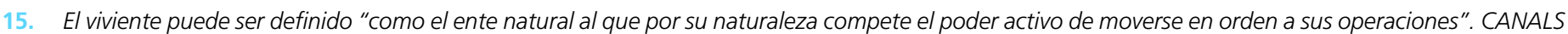
VIDAL 1987, p. 585. Ahora bien, los vivientes son los seres que se dan a sí mismos el movimiento bien se tome como acto de lo imperfecto, es decir, de lo que está en potencia, o bien como acto de lo perfecto, en cuyo caso también se denominan movimientos los actos de entender y amar. Cf. S. Th. I, q. 9, a 1, ad 1; q. 14, a. 1; q. 18, a. 3, ad 1.

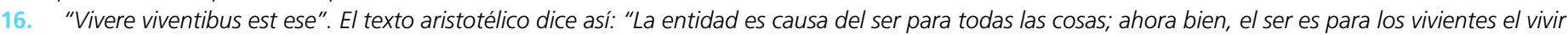
y el alma es su causa principio". Aristóteles, De anima, II, c. 4, 415b 13-14. Santo Tomás de Aquino comenta: "Aquello es causa de algo en cuanto substancia, es decir, como forma, que es la causa del ser. Pues por la forma cada uno está en acto. Pero el alma de los vivientes es causa del ser; pues por el alma viven, y el mismo vivir es su ser. Luego, el alma como forma es causa del cuerpo de los vivientes". In De Anima, n. 319.

17. S. Th. I, q. 4, a. 2, ad 3 .

18. SCG, I, 28.

19. CANALS VIDAL p. 257.

20. S. Th. I. q, 18, a. 2.

21. Cf. S. Th. I, q. 18, a. 2 
"En Dios es lo mismo el entendimiento, el acto de entender y lo entendido. Por eso, todo lo que hay en Dios como entendido es su vida y su mismo vivir. Por eso, como todas las cosas son hechas por Dios y están en él como entendidas se sigue que todas las cosas que están en él son la misma vida divina"22.

Sto. Tomás afirma que en Dios se identifica su ser, su entender y su vida, de tal manera que la vida perfecta divina es vida del intelecto. Por ello, explica el Aquinate que el entendimiento humano no posee una vida que sea total autoposesión e intimidad del ser que le haga totalmente autónomo, en cambio en Dios toda su vida es su mismo ser y entender ${ }^{23}$. Pero añade el Aquinate que la acción de entender por su propia naturaleza no es operación que pase a materia exterior, sino acción que permanece perfeccionado al sujeto que la ejecuta. Es acto de lo perfecto ${ }^{24}$.

"Como se ha indicado el entender no es acción que pase a algo extrínseco, sino que permanece en el operante como su acto y perfección en cuanto que el ser es perfección del existente, ya que como el ser sigue a la forma así el entender sigue a la especie inteligible. Pero en Dios no hay una forma que sea distinta de su ser, como hemos dicho. Por eso, como su misma esencia sea su especie inteligible, como se ha dicho, es necesario que su entender sea su esencia y su ser. Por ello, es patente que en Dios el intelecto y aquello que entiende y la especie inteligible sean en todo lo uno y lo mismo. Por eso, Dios se llama inteligente y ninguna multiplicidad se pone en su substancia" 25 .

Ahora bien, el entendimiento humano en la acción de entender son distintos el entendimiento y la especie inteligible, ya que la especie inteligible informa el entendimiento para conocer en acto, pero no así en Dios donde su especie inteligible se identifica con su ser.

"Pero como en Dios no hay potencialidad, sino que es acto puro es necesario que en él el intelecto y lo entendido sean lo mismo de todas maneras. De tal modo, que no carezca de especie inteligible como le ocurre a nuestro intelecto cuando está en potencia para entender. Ni tampoco la especie es distinta de la substancia del intelecto divino, como acontece en nuestro intelecto cuando es en acto inteligente. Pero la misma especie inteligible es el mismo intelecto divino. Y por eso, Dios a sí mismo se entiende por sí mismo"26.

Esta perfecta identificación en Dios de su ser con su acción de entender exige que se identifique su entendimiento con la misma especie inteligible en la posesión intima de su ser, que como veremos en lo que sigue, se identifica con la misma persona del Verbo.

\section{ACCIÓN DE ENTENDER Y GENERACIÓN DEL VERBO}

El Aquinate pone en el orden de la actividad intelectual el fundamento u origen de esta procedencia de un término desde otro, y por cuya actividad intelectual se "produce una asimilación del cognoscente a lo conocido" 27 . Ya hemos dicho, que la intención del Aquinate no es probar que existe un verbo personal en Dios, sino mostrar la congruencia de la analogía del verbo interior finito con el Verbo personal. En esto, Sto. Tomás sigue el camino abierto por San Agustín que procede a manifestar la trinidad de personas a partir de la procesión del verbo y el amor en nuestra mente ${ }^{28}$.

Ahora bien, si hay una procesión u origen en la divinidad es porque hay una acción que es el origen de ella, "pues todo origen se designa por algún acto" ${ }^{29}$. Esta acción es la misma actividad intelectual del agente divino como inteligente en acto. Para el Aquinate en Dios se identifican el ser y su entender, de tal modo que no hay ninguna perfección en Dios que no sea su substancia ${ }^{30}$. En este sentido se refiere a los herejes que negaron la igualdad del Hijo con el Padre como aquellos que entendieron esta procesión de modo transeúnte, es decir, como algo que pasa desde una realidad a otra realidad. Así Arrio igualó la procesión del Hijo "como el efecto procede de la causa ${ }^{31 ", ~ y ~ p o r ~}$ eso, para él el Hijo era la primera criatura del Padre. A su vez Sabelio, célebre modalista, entendió que "la causa procede hacia el efecto"32", al entender que el Hijo era el mismo Padre en cuanto que se hace hombre. Ambos modos de entender las procesiones revelan que las entendieron como algo que termina en el exterior ${ }^{33}$. Por eso, negaron a la vez la igualdad y diferencia de las personas divinas como también la existencia de procesiones inmanentes en Dios. Para el Aquinate la procesión del Verbo no puede ser sino una actividad que nace en el

22. S. Th. I, q. 18, a. 4.

23. El entendimiento humano se mueve a sí mismo de un modo más perfecto que los vegetales y los animales, pues la facultad intelectual humana se mueve a sí misma desde sí misma y mueve las demás potencias. Pero el entendimiento humano, aunque pueda dirigir otras facultades, sin embargo, la naturaleza le impone ciertos principios naturalmente conocidos de los cuales no puede desprenderse y es dirigido por ellos. Junto a los principios primeros está la orientación al fin último que el hombre no puede no querer y, por lo tanto, con respecto a los primeros principios y el fin último el hombre es movido y no puede determinarse desde sí mismo. Por ello, concluye el Aquinate que en Dios está el supremo grado de vida, pues para conocer no es determinado por algo ajeno a él mismo. Cf. S. Th. I, q. 18, a. 3.

24. Cf. S. Th. I, q. 18, a. 3, ad 1.

25. S. Th. I, q. 14, a.4.

26. S. Th. I, q. 14, a.2.

27. De Veritate. q. 8, a. 5 .

28. Cf. S. Th. I, q. 32, a. 1., ad 2

29. S. Th. I, q. 41, a. 1.

30. Cf. S. Th. I, q. 14, a. 2 et 4.

31. S. Th. I, q. 27, a.1.

32. S. Th. I, q. 27, a.1.

33. Cf. In III Sent. d. 13, q. 1, a. 1; Cf. S. Th. I, q. 27, a.1 ad, 1. 
interior de Dios y que termina en él mismo. La procesión que tiene lugar en Dios se apoya sobre la acción de entender que se identifica con su ser, ya que todo en Dios es su ser ${ }^{34}$. Por eso, en la acción de entender que procede desde la interioridad en acto y que permanece en ella es la que da lugar a esta procesión. Veamos ahora un texto central del Aquinate sobre esta cuestión:

Por eso, "en quienquiera que entienda, por lo mismo que entiende, procede algo en su interior, que es la concepción de la cosa entendida, que proviene de su fuerza intelectiva y que procede de su noticia. Cuya concepción es la que significa la voz y se llama verbo del corazón, significado verbo de la voz ${ }^{35 "}$.

El Aquinate afirma que, en cualquier sujeto intelectual por el mismo hecho de entender, se origina un efecto de este mismo entender, que es la concepción de la cosa entendida, y que proviene de la misma potencia de entender como su efecto propio originado en la misma actualidad del sujeto ${ }^{36}$. Esta concepción de la cosa entendida se llama propiamente concepto o verbo interior o verbo del corazón, pues se origina en la misma plenitud entitativa del sujeto intelectual y que brota de su acto de entender y por medio del cual se conoce lo que se conoce. Comenta Canals Vidal, inspirado en Juan de Santo Tomás ${ }^{37}$, que pertenece a la misma esencia del conocimiento la actividad concipiente y formativa de un concepto que es semejanza de la cosa conocida. "Afirmar que el conocimiento intelectual es por su misma naturaleza concipiente y judicativo, manifestativo de lo que conoce en la locución mental, o lo que es lo mismo, afirmar que en su esencia la actividad pensante emana de la plenitud y actualidad del entender, equivale a presuponer, o mejor diríamos simplemente a constatar y reconocer, que el entendimiento dice porque conoce y en cuanto que conoce, y por ello, orientarse a buscar la actualidad, que hace al entendimiento fecundo para decir, en la posesión del ente en su ser, en la conciencia pensante como originadora del pensamiento concebido" ${ }^{38}$. El intelecto mismo en su razón formal de intelecto es formativo y concipiente de un verbo mental por medio del cual se expresa y manifiesta lo que es $^{39}$. El intelecto por su misma actualidad cognoscitiva es fecundo y manifestativo de lo que es por medio de su concepto por el cual se capta lo que es ${ }^{40}$. Ahora bien, este concepto mental no emana de la actividad intelectual en cuanto potencia para lo que es ni por razón de una indigencia ontológica, sino desde su propia actualidad referida y abierta de suyo a todo ente. Pero existe una diferencia entre este concepto que brota de la actualidad de un ser finito y la de un ser infinito. Pues el verbo se origina como algo que procede de un intelecto finito en cuanto que es actuado desde fuera por las especies que el intelecto recibe desde las cosas sensibles ${ }^{41}$. En cambio, el intelecto divino no es actuado por nada que le sea extrínseco, sino que la concepción del intelecto brota desde la más absoluta inmanencia y posesión de sí del objeto cognoscitivo divino. Ahora bien, a pesar de que nuestro intelecto finito sea puesto en acto en cuanto sujeto potencial, el verbo mental surge en nosotros en cuanto que el alma humana es un ser en acto $^{42}$. El verbo mental nace en nosotros y en Dios, manteniendo la analogía correspondiente, en cuanto que el sujeto es ya un existente en acto $^{43}$. Toda actividad formativa de un concepto se origina en la actividad de una naturaleza activa "y procede de su noticia" 44 . Esta afirmación de la presencia de una naturaleza activa por su mismo carácter no es sino la constatación de un conocimiento habitual del

34. Cf. S. Th. I, q. 3, a. 4.

35. "Quicumque enim intelligit, ex hoc ipso quod intelligit, procedit aliquid intra ipsum, quod est conceptio rei intellectae, ex vi intellectiva proveniens, et ex eius notitia procedens. Quam quidem conceptionem vox significat, et dicitur verbum cordis, significatum verbo vocis". S. Th. I, q. 27, a. 1

36. Pues el carácter locutivo y formativo de una especie o verbo por el cual se entiende todo lo que se entiende es una verdad filosófica que pertenece al concepto de inteligente en cuanto inteligente.

37. Canals Vidal ha llamado la atención no sólo de la pérdida del lenguaje mental en el seno de la tradición escolástica y tomista, sino también que el célebre comentarista Juan Poinsot siempre se mantuvo fiel a la doctrina del Aquinate sobre el carácter esencialmente locutivo y manifestativo de la verdad del ente del conocimiento humano. Para Juan Poinsot el verbo mental es aquello que es formado por el entender en acto mediante el lenguaje mental "en la medida y por razón de su actualidad y perfección consciente, no ex indigentia, sino ex plenitudine notitae. La formación ex indigentia es la formación en cuanto imperfecta; pero la formación es ex plenitudine en cuanto que, lejos de suponer imperfección ni potencialidad en el cognoscente y en lo conocido, se sigue necesariamente a su actualidad". CANALS VIDAL. 1987, p. 229.

38. CANALS VIDAL 1987, p. 257.

39. Puede el intelecto humano conocer la realidad y aprehenderla a partir de los datos que los sentidos le proporcionan por medio del concepto. El conocimiento intelectual humano es mediato y directo de las realidades conocidas porque conoce elaborando un verbo mental. El conocimiento humano no es intuitivo de esencias que se le representan a su propia entidad cognoscitiva, sino que conoce mediante conceptos. Y esta aprehensión de la realidad se da o tiene lugar en el acto de conocimiento que por su propia naturaleza es formativo de un verbo. Por ello, el conocimiento humano no sólo alcanza lo real, sino que lo real se expresa locutivamente en el pensamiento cuando dice lo que es. Tal es la centralidad del llamado "realismo pensante" de Canals Vidal, para quien lo real se expresa en el pensamiento humano fecundo y concipiente de la realidad misma a través del verbo mental.

40. El verbo interior es manifestativo de lo que es, pues el verbo no sólo pone en acto el intelecto haciéndole conocer en acto, sino que también manifiesta lo que está en el intelecto. De Veritate q. 4, a. 3, ad 4.

41. Todo nuestro conocimiento se origina en los seres sensibles. La sensibilidad en el hombre es necesaria para conocer sólo por relación al objeto que es proporcionado a un alma unida a un cuerpo, que es la esencia sensible que existe en las cosas materiales. Cf. S. Th. I, q. 75, a. 2, ad. 3: "Para la actividad del entendimiento se precisa del cuerpo, no como de un órgano por el cual la operación se realice, sino por razón del objeto, cuya representación en la imagen es para el entendimiento lo que el color para la vista", que es la esencia abstracta de la cosa material y representada por la imaginación. Cfr. S. Th. I, q. 84, a. 7; De Veritate, q. 10, a. 1.

42. Cf. SCG. IV, 11.

43. Sobre el valor y sentido de la analogía del verbo mental. Cf. IZQUIERDO 1982/2, pp. 574-579.

44. S. Th. I, q. 27, a. 1. 
sujeto cognoscente desde cuyo conocimiento fecundo brota el verbo como su efecto propio. $Y$ en cuyo verbo el inteligente entiende todo lo que entiende ${ }^{45}$. Veamos otro texto que nos introduce directamente en la procesión del Verbo divino.

"Es manifiesto que una cosa cuanto más se entiende, la concepción intelectual es tanto más íntima al inteligente y más una con él; pues el intelecto según que entiende en acto se hace uno con lo entendido. De aquí que como el intelecto divino sea la suma perfección es necesario que el verbo divino sea perfectamente uno con aquel del cual procede, sin ninguna diversidad" ${ }^{46}$.

El Aquinate nos ilustra en este texto sobre la diferencia del verbo divino y el verbo interior proferido por un intelecto finito. Esta diferencia viene descrita en términos de una mayor intimidad entre el inteligente y lo por él proferido. Ahora bien, este texto debemos complementarlo con el lugar paralelo de Suma contra gentiles IV, 11, donde la generación divina es descrita en términos de emanación intelectual. En un orden ascendente el Aquinate mostrará que a diversas naturalezas son diversos los modos de emanación ${ }^{47}$. A mayor perfección de ellas es más íntimo lo que de ellas emana como fruto y expresión de la actualidad de su ser. De esta manera, el Aquinate mostrará desde la analogía de los grados de emanación entre las diversas naturalezas una vía de comprensión del misterio de la generación divina del Verbo. El Aquinate comienza describiendo la actividad de los cuerpos inanimados que no poseen una capacidad de causalidad que opere desde el interior, sino que su actividad se limita a actuar unos sobre otros. Luego aparecen en esta escala de seres los cuerpos animados, cuyo lugar próximo lo constituyen las plantas que poseen una capacidad de emanación "desde dentro", pues su humor interno se convierte en semilla y luego pasa al exterior para convertirse en planta. Sin embargo, la vida de las plantas es el grado más ínfimo, pues si bien es cierto que lo que emana procede desde dentro, no obstante, queda fuera de ellas. Hay otro grado de vida superior a las plantas y es el que corresponde a la vida animal, dotada de alma sensitiva, cuya propia emanación que, aunque comienza en el exterior termina en el interior. Pues lo sensible exterior imprime su forma en los sentidos externos para luego pasar a la imaginación, donde la forma se archiva y conserva en la imaginación. Sin embargo, la potencia sensitiva está limitada en su actualidad, pues no puede volver sobre sí misma. Finalmente hay un supremo grado de vida que corresponde a la vida intelectual, ya que vuelve sobre sí misma y puede entenderse ${ }^{48}$. Pero, aunque el entendimiento humano tiene la capacidad de entenderse a sí mismo, no obstante, el principio de su conocimiento se encuentra en lo exterior, en la representación sensible que se presenta a sus sentidos. Por eso, la vida intelectual de los ángeles es más perfecta que la vida racional de los hombres, pues su entendimiento no tiene su punto de partida en algo exterior para conocerse, pues el ángel se conoce por su misma esencia ${ }^{49}$. Sin embargo, su vida no alcanza la última perfección posible, ya que, aunque la idea entendida sea en ellos totalmente intrínseca, sin embargo, su entender no es su propia esencia, ya que en ellos el ser no se identifica con su esencia. Por ello, la última perfección del conocer se encuentra en Dios, que es el mismo Ser Subsistente. Después de este breve itinerario podemos comprender, "que una cosa cuanto más se entiende, la concepción intelectual es tanto más íntima al inteligente y más una con él; pues el intelecto según que entiende en acto se hace uno con lo entendido" ${ }^{50}$. La concepción intelectual será más perfecta cuanto que emana de modo más íntimo desde el sujeto inteligente y posee más unidad con el principio desde donde emana. Esta máxima intimidad y unión con el principio desde el que emana se da en el intelecto divino que profiere el Verbo mental en semejanza perfecta con el principio desde el que brota. Para el Aquinate la generación del Verbo en la intimidad es semejante analógicamente la emanación del verbo mental en el cognoscente intelectual finito.

Ahora bien, en la toda naturaleza intelectual concipiente y fecunda se debe distinguir entre la intentio intellecta que es "a aquello que el entendimiento concibe en sí mismo de la cosa entendida" , o verbo interior ("la misma intentio se llama verbo interior, que es significado por el verbo exterior" ${ }^{52}$ ); de la species intelligibile tanto en la naturaleza divina como en el sujeto intelectual finito ${ }^{53}$.
"Esta intentio entendida, que es como término de la operación in- telectual, es distinta de la especie inteligible, que hace al intelecto en acto, y que es necesario que sea considerada como el principio de la operación intelectual. Aunque ambos sean una semejanza de la cosa entendida. Por lo que la especie inteligible, que es for-

45. El verbo mental no es aquello por lo que se conoce, sino el medio por el que se conoce y es el medio por el cual se informa el intelecto humano haciéndolo ser en acto. Dios no obstante conoce por su propia esencia. "Ad tertium dicendum, quod conceptio intellectus est media inter intellectum et rem intellectam, quia ea mediante operatio intellectus pertingit ad rem. Et ideo conceptio intellectus non solum est id quod intellectum est, sed etiam id quo res intelligitur; ut sic id quod intelligitur, possit dici et res ipsa, et conceptio intellectus; et similiter id quod dicitur, potest dici et res quae dicitur per verbum, et verbum ipsum; ut etiam in verbo exteriori patet; quia et ipsum nomen dicitur, et res significata per nomen dicitur ipso nomine". Cf. CANALS VIDAL. 1987, pp. 83-88.

46. S. Th. I, q. 27, a. 1 ad 2.

47. Sobre el uso y origen del término emanación en la obra del Aquinate ver, CRUZ CRUZ 2000, pp. 461-490.

48. Sobre el sentido de la llamada reflexión del alma humana que consiste en un volver sobre la imagen presentada por la fantasía y que se expresa de modo conceptual como un retorno al centro inteligible desde el que emana el acto de intelección ver, CANALS VIDAL 1987, pp. 113-118.

49. Cf. S. Th. I, q. 87, a. 1, ad 2.

50. S. Th. I, q. 27, a. 1 ad 2.

51. "Est autem de ratione interioris verbi, quod est intentio intellecta, quod procedat ab inteligente secundum suum intelligere, cum sit quasi terminus intellectualis operationis: intellectus enim intelligendo concipit et format intentionem sive rationem intellectam, quae est interius verbum". SCG IV, 11, ก. 6 .

52. "Unde et ipsa intentio verbum interius nominatur, quod est exteriori verbo significatum". SCG IV, 11, n. 6.

53. La species intellibilis todavía no es inteligible en acto, sino sólo en potencia. Cf. CANALS VIDAL 1987, pp. 436. 457. 
ma del intelecto y principio del entender, es semejanza de la cosa exterior. De aquí se sigue que la intentio entendida forme aquella semejanza de la cosa porque tal como es cada uno así obra. Y por esto, como la intentio entendida es similar a la cosa, se sigue que el intelecto, formando tal intentio, entienda aquella cosa" ${ }^{54}$.

De la species intelligibilis nos dice que su función es colocar al intelecto finito en acto y es "principio de la operación intelectual" 55 . El intelecto finito en virtud de la especie inteligible conoce y entiende en virtud de la actividad del intelecto agente, ya que la specie intelligibilis no posee todavía el ser inteligible ${ }^{56}$. Para Sto. Tomás esta species intelligibilis no se identifica ni es el mismo fantasma o imagen ${ }^{57}$, sino que su función es hacer presente en el cognoscente el objeto conocido, la species no es lo que se conoce, sino el medio para conocer ${ }^{58}$. La species intelligibilis es el principio del conocer porque por su posesión el sujeto conoce y se opera el acto cognoscitivo, y por lo mismo es lo que secundariamente se conoce ${ }^{59}$.

"Porque el intelecto sobre sí mismo reflexiona y según la misma reflexión entiende y entiende su entender y la especie por la cual entiende. Y así la especie intelectiva es lo que secundariamente se entiende. Pues aquello que se entiende primariamente es la cosa cuya semejanza es la especie inteligible" 60 .

Sin embargo, en la naturaleza divina la species intelligibilis es la misma esencia divina por la cual es en acto. En Dios la species intelligibilis es el principio de la operación intelectual que culmina en la formación del verbum mentis. Y sin esta actualización no habría intelección de lo real, tanto en Dios como en la criatura finita, que es aquello a lo que se orienta toda actividad intelectual. De la intentio intellecta nos dice que es el término de la operación intelectual, es su resultado o efecto en virtud de la información de la species intelligibilis. Es el verbum cordis o intentio intellecta el que es semejanza de la cosa conocida y por ello, es idéntica y "similar a la cosa" cuya existencia es inmaterial. De este modo, la species intelligibilis es la forma intencional que informa el entendimiento posible (en el hombre, no en Dios), poniendo en marcha la formación de la intentio intellecta o verbo interior. Por ello, el intelecto (posible) al ser informado por la species intelligibilis forma un verbo interior, que es semejanza de la cosa entendida y en la que entiende la cosa. "Después hay que considerar que el intelecto, por la especie formada de la cosa, entendiendo forma en sí mismo alguna intentio de la cosa entendida, que es su razón, que se significa por la definición" ${ }^{61}$. Esta species intelligibilis en la criatura racional tiene la función de actualizar el llamado intelecto posible que es la función potencial que posee nuestro modo finito de entender ${ }^{62}$. Pues el entendimiento humano, cuando es informado por la species intelligibilis no hace sino pasar de la potencia al acto en virtud de dicha actualización ${ }^{63}$. Se debe considerar al respecto que "entendimiento posible y entendimiento agente no difieren entre sí como dos 〈potencias〉 del alma intelectiva, sino que son, en el orden de la perfección inteligible - posesión consciente infinitamente abierta a todo ente - la potencialidad o capacidad receptiva de formas - en una substancia inmaterial carente de ellas y destinadas a recibirlas por la vía del conocimiento sensible - y la virtud activa consistente en el acto o «sers inteligible, poseído connaturalmente por la mente con anterioridad a toda recepción, y constituyendo incluso la raíz entitativa de la que emana la propia capacidad receptiva del entendimiento posible" ${ }^{\prime 64}$. En la línea de la potencialidad propia del intelecto finito y el carácter accidental del acto de conocer debemos reconocer la existencia de la función pasiva y activa del intelecto finito. En la misma línea de la finitud del conocimiento hay que sostener el carácter de accidente e inherente en el sujeto del acto de conocer, ya que de lo contrario habría que decir que el mismo conocer sería el ser de ese sujeto, cuestión que sólo es verdad en el ser infinito que es Dios ${ }^{65}$. El carácter de accidente que posee el conocimiento en una substancia finita no impide afirmar que el objeto es lo formado por el conocimiento mismo. Y la intentio intellecta es el verbo en el

54. "Haec autem intentio intellecta, cum sit quasi terminus intelligibilis operationis, est aliud a specie intelligibili quae facit intellectum in actu, quam oportet considerari ut intelligibilis operationis principium: licet utrumque sit rei intellectae similitudo. Per hoc enim quod species intelligibilis quae est forma intellectus et intelligendi principium, est similitudo rei exterioris, sequitur quod intellectus intentionem formet illi rei similem: quia quale est unumquodque, talia operatur. Et ex hoc quod intentio intellecta est similis alicui rei, sequitur quod intellectus, formando huiusmodi intentionem, rem illam intelligat". SCG I, 53, n. 4.

55. Cf. SCG I, 46, n. 2. "Intellectus enim non potest intelligere nisi secundum quod fit in actu per per hanc similitudinem, sicut nihil aliud potest operari secundum quod est in potentia, sed secundum fit actu per aliquam formam. Haec ergo similitudo se habet in intelligendo sicut intelligendi principium, ut calor est principium calefactionis, non sicut intelligendi terminus". De Potentia q. 9, a. 5.

56. "Per speciem intelligibilem fit intellectus intelligens actu: sicut per speciem sensibilem sensus actu sentiens". SCG I, 46, n. 3 .

57. Cf. S. Th. 1, q. 85, a. 2, ad 4.

58. Cf. S. Th. I, q. 76, a. 2, ad 2. "La especie inteligible se relaciona con el intelecto como aquello por lo cual el intelecto entiende". S. Th. I, q. 85, a. 2.

59. Tomàs de Aquino distingue entre el acto de conocer, que proviene del intelecto en acto, de aquello que es entendido, y de la especie inteligible, que es aquello por lo cual el intelecto es informado y todavía más del verbo mental, que es fruto final del intelecto fecundo. Cf. De Potentia q. 8, a. 1.

60. S. Th. I, q. 82, a. 2.

61. "Ulterius autem considerandum est quod intellectus, per speciem rei formatus, intelligendo format in seipso quandam intentionem rei intellectae, quae est ratio ipsius, quam significat definition". SCG I, 53, n. 3.

62. Que el conocimiento de un ser finito es algo sobrevenido a él es por la limitación del ser en su substancia creada, que exige que el intelecto sea actualizado desde fuera por las especies sensibles en su actual condición corpórea, pero esto no está en la línea de lo que es la esencia del conocimiento, sino del modo finito como se participa de la perfección del conocimiento. CANALS VIDAL 1981, pp. 21. 23.

63. Pues el intelecto humano en virtud de su finitud entitativa implica siempre una dimensión de potencialidad y en esta verdad se funda la negación que el entendimiento humano tenga por su propia esencia la actual intelección de sí mismo. Pues para tal actualización se requiere que el entendimiento haya sido puesto en acto por las especies abstraídas de lo sensible. Cf. CANALS VIDAL 1987, pp. 456-460.

64. CANALS VIDAL 1987, p. 460. "El intelecto agente y el posible no difieren entre sí como un 〈ente> de otro <ente〉, sino como la potencia y el acto en el seno de la naturaleza infinita del ente inmaterial participada según el modo humano". CANALS VIDAL. 1981, p. 39.

65. Cf. CANALS VIDAL 1981, p. 21. 
cognoscente finito, formado por la misma operación del intelecto y que es formado por el llamado intelecto agente, acto de todos los inteligibles. Ya que en el intelecto finito no sólo existe esta función de pasividad en virtud de la cual necesita ser actualizado, sino que también participa de la infinitud del acto ${ }^{66}$ por medio del intelecto agente, acto de los inteligibles. Si el intelecto humano finito no participase de esta infinitud del acto, por el cual es acto de los inteligibles, no podría formar la intentio intellecta como perfección intencional en cuanto que el cognoscente finito posee una luz que manifiesta lo que es. Por eso, enseña el Aquinate que esta intentio intellecta, tanto en el intelecto finito como infinito, no se forma pasando de la potencia al acto sino en cuanto que éste ya existe en acto.

"El intelecto divino no entiende por ninguna otra especie sino por su esencia. Pero, sin embargo, su esencia es semejanza de todas las cosas. Por esto, se sigue que la concepción del intelecto divino por el que se entiende a sí mismo, que es su verbo, no sólo es la semejanza del mismo Dios entendido, sino también de todas las cuales la esencia divina es semejante. Y así por una especie inteligible, que es la esencia divina, y por una intentio entendida, que es el verbo divino, muchas cosas pueden ser entendidas por Dios" ${ }^{\prime \prime 7}$.

Si en el ámbito de la finitud del sujeto inteligente la species intellecta es la que actualiza el entendimiento posible, en Dios esta species es la misma esencia divina y tanto por ella como por la intentio intellecta muchas cosas pueden ser entendidas por Dios. Pues, Dios entiende todo por su misma esencia

"El intelecto divino no entiende su esencia por alguna especie diferente esencial o realmente de la misma esencia, sin embargo, entiende su esencia por su misma esencia. Por eso, la esencia se tiene como el inteligente y lo entendido y aquello por lo cual se entiende. En cuanto que se tiene como inteligente allí hay propia y verdaderamente razón de inteligente. En cuando que se tiene como aquello que se entiende hay ahí propia y verdadera de razón entendida. Pero en cuanto se tiene como aquello por lo que se entiende hay allí razón de verbo" ${ }^{\prime 68}$.
Hay que afirmar que la formación de un verbo interior o mental en el que se conoce todo lo que se conoce pertenece a la esencia del conocimiento en cuanto tal, y que el conocimiento mediante la mediación pensante no constituye ninguna caída ontológica del cognoscente finito. El carácter locutivo y manifestativo del conocimiento humano pertenece a la naturaleza misma del conocimiento en cuanto tal. "El concebir no es, pues, para Santo Tomás ni un sucedáneo al que haya que conformarse por falta de perfección intuitiva del conocer, ni algo esencialmente subordinado y al servicio de la intuición. La actividad concipiente y pensante se funda en la fuerza misma del entendimiento en su naturaleza activa; y procede de su noticia, y no es por lo mismo, algo exigido por la carencia de relación inmediata a la realidad conocida, como algo sustitutivo de la cercanía o posesión entitativa" ${ }^{\prime \prime}$.

A partir de estos presupuestos gnoseológicos podemos entender qué es la generación del Verbo para el Aquinate.

"En Dios donde se identifican el inteligente y el entender y la intentio entendida, que es el mismo verbo, es preciso que verdaderamente esté presente en Dios lo que pertenece a la razón de inteligente, y lo que pertenece a la razón de entender, y lo que pertenece a la razón de intentio entendida y verbo. Pues es de la razón de verbo interior, que la intentio entendida que procede de un inteligente según su entender, que sea como el término de la operación intelectual. Ya que el intelecto entendiendo concibe y forma la intentio o razón entendida, que es el verbo interior. Luego es necesario que en Dios proceda su Verbo según su entender. Por lo tanto, el Verbo de Dios es comparado con Dios inteligente como el término con respecto a su principio, ya que esto es de la naturaleza de todo verbo. En consecuencia, como en Dios sean en esencia uno el inteligente, el entender y la intentio entendida o el Verbo, por eso, en necesario que cada uno de estos sea Dios. Sin embargo, permanece la sola distinción por la relación en cuanto que el Verbo se refiere al concipiente como aquel del cual es. Esto es lo que el Evangelista dijo: Dios era el Verbo, y para que no entienda que no había distinción en el Verbo y Dios, añadió: Este era en al principio en Dios, como si dijera: Este Verbo, que dije era Dios, es de algún modo distinto de Dios dicente, para que pueda afirmarse que estaba en Dios"70.

66. "Intelligere de sui ratione, habet infinitatem simpliciter". S. Th, I, q. 54, a 2.

67. "Intellectus autem divinus nulla alia specie intelligit quam essentia sua, ut supra ostensum est. Sed tamen essentia sua est similitudo omnium rerum. Per hoc ergo sequitur quod conceptio intellectus divini, prout seipsum intelligit, quae est verbum ipsius, non solum sit similitudo ipsius Dei intellecti, sed etiam omnium quorum est divina essentia similitudo. Sic ergo per unam speciem intelligibilem, quae est divina essentia, et per unam intentionem intellectam, quae est verbum divinum, multa possunt a Deo intelligi". SCG I, 53, n. 5.

68. "Ad quartum dicendum, quod intellectus divinus non intelligit essentiam suam per aliquam speciem differentem essentialiter aut realiter ab ipsa essentia; nihilominus tamen ipse intelligit essentiam suam per essentiam suam; unde essentia se habet ut intelligens et ut intellecta et ut quo intelligitur; et inquantum se habet ut intelligens, sic vere et proprie est ibi ratio intellectus; et inquantum se habet ut id quod intelligitur, est ibi vere ratio intellecti; sed inquantum se habet ut quo intelligitur, sic est ibi ratio verbi". In I Sent. d. 27 q. 2 a. 1 ad 4.

69. CANALS VIDAL 1987, p. 258.

70. "Oportet igitur, cum in Deo sit idem intelligens, et intelligere, et intentio intellecta, quod est verbum ipsius; quod verissime in Deo sit et quod pertinet ad rationem intelligentis; et quod pertinet ad rationem eius quod est intelligere; et quod pertinet ad rationem intentionis intellectae, sive verbi. Est autem de ratione interioris verbi, quod est intentio intellecta, quod procedat ab intelligente secundum suum intelligere, cum sit quasi terminus intellectualis operationis: intellectus enim intelligendo concipit et format intentionem sive rationem intellectam, quae est interius verbum. Oportet igitur quod a Deo secundum ipsum suum intelligere procedat verbum ipsius. Comparatur igitur verbum Dei ad Deum intelligentem, cuius est verbum, sicut ad eum a quo est: hoc enim est de ratione verbi. Cum igitur in Deo intelligens, intelligere, et intentio intellecta, sive verbum, sint per essentiam unum, et per hoc necesse sit quod quodlibet horum sit Deus; remanet tamen sola distinctio relationis, prout verbum refertur ad concipientem ut a quo est. Hinc est quod Evangelista, quia dixerat, Deus erat verbum; ne omnino distinctio sublata intelligeretur verbi a Deo dicente sive concipiente verbum, subiunxit: hoc erat in principio apud Deum: quasi dicat: hoc verbum, quod Deum esse dixi, aliquo modo distinctum est a Deo dicente, ut sic possit dici apud Deum esse". SCG. IV, 11, 
Por tanto, en Dios son lo mismo el que entiende, el inteligente, el acto de entender y el verbo proferido por la misma actualidad del inteligente, que es el fruto y término de esa actualidad. Este Verbo proviene de aquella actualidad del acto puro, el mismo Ser subsistente, donde se identifican el ser y el entender con la vida divina ${ }^{71}$, y a Él queda referido por la sola relación. Y de esta manera, "el mismo Verbo de Dios por lo mismo que es Dios entendido es verdadero Dios que tiene naturalmente el ser divino, ya que en Él no es distinto el ser natural de Dios que su entender" ${ }^{\prime 72}$. A la esencia del entender pertenece que sea comunicativo de su perfección, ya que el acto por su propia naturaleza es comunicativo y fecundo. Para el Aquinate la formación del verbo interior no es un movimiento ni acción predicamental, sino que es una acción que es un acto de lo perfecto, que nace de un acto, y emana su efecto como fruto de su actualidad. Pues la formación de este verbo interior es un acto perfecto donde no se encuentra ninguna razón de potencialidad ni imperfección. "Es patente que en Dios la generación intelectual que afirmamos no es tal como en las cosas materiales, cuya generación es una mutación, que es lo opuesto a la corrupción"73. Pues, la generación en el ámbito de los cambios naturales supone la potencialidad del móvil, en cambio, la generación del verbo es una emanación intelectual que por su propia naturaleza es acto que proviene de un acto. "Es por la fecundidad vital infinita del acto puro en la línea intelectual, por la que podemos referirnos al Verbo e Hijo como Luz de Luz, nacido del Padre antes de todos los siglos, Hijo Unigénito de Dios, de la misma naturaleza que el Padre, Dios de Dios, que la revelación del misterio nos propone a nuestra fe y que la razón al servicio de la fe puede expresar hablando del surgir el Acto del Acto"74.

"Igualmente el verbo que es concebido en nuestra mente no pasa de la potencia al acto, salvo en el caso de nuestro intelecto que procede de la potencia al acto. Ni tampoco se origina en nuestro intelecto sino en cuanto que existe en acto, pues igual cuando existe en acto está en él el verbo concebido. Ahora bien, el intelecto divino nunca está en potencia, sino sólo en acto. Así pues, la generación del Verbo mismo no es según el paso de la potencia al acto, sino como se origina el acto del acto, el esplendor de la luz, y el concepto entendido desde el intelecto en acto. $Y$ esto muestra que la generación no prohíbe que el Hijo de Dios sea verdadero Dios o el mismo ser eterno. Más bien, es necesario que sea el mismo coeterno con Dios, del cual es Verbo porque el intelecto en acto nunca está sin verbo"75.

De esta manera, el Aquinate puede justificar racionalmente, apoyado en la analogía de la fecundidad de la inteligencia que forma un verbo como manifestación de su actualidad entitativa, que en Dios hay un Verbo, que procede como "Dios entendido" por medio de un parto inteligible. Que se encuentra ontológicamente más allá de aquella generación de los entes naturales en quienes la generación supone la potencialidad, como acto de un móvil en cuanto que está en potencia. Esta generación inteligible que no está sometida a las condiciones de las cosas móviles es por vía de generación inteligible. El Hijo recibe todo del Padre por medio de su acción de entender, plenamente fecunda, que es un acto intrínseco de un ser subsistente, que se identifica con su esencia. Esta concepción inteligible sucede sin mutación, pues procede de acto a acto, en la intimidad del mismo Ser subsistente, que cuando es concebido es y es cuando es dado a luz como concebido distinto al generante, de igual manera que como cuando algo es iluminado al mismo tiempo que se ilumina queda iluminado.

"De aquí que después de haber dicho por boca de la Sabiduría: Antes que fueran los collados, yo era dada a luz, con el fin de que no se entienda que, mientras no era dada a luz, no fuese, se añade: Cuando fundó los cielos, allí estaba yo"

\section{GENERACIÓN DIVINA Y PROCESIÓN DEL VERBO}

El término generación significa, en el ámbito de los seres naturales móviles, en virtud de su principio intrínseco de movimiento, el paso del no-ser al ser o del ser al no-ser, y es lo que Aristóteles entiende por generación absoluta o cambio substancial, que es la adquisición o pérdida

71. "Cum autem intellectus divinus non solum sit semper in actu, sed etiam sit ipse actus purus, ut in primo probatum est; oportet quod substantia intellectus divini sit ipsum suum intelligere, quod est actus intellectus; esse autem verbi interius concepti, sive intentionis intellectae, est ipsum suum intelligi. Idem ergo esse est verbi divini, et intellectus divini; et per consequens ipsius Dei, qui est suus intellectus. Esse autem Dei est eius essentia vel natura, quae idem est quod ipse Deus, ut in primo ostensum est. Verbum igitur Dei est ipsum esse divinum et essentia eius, et ipse verus Deus". SCG. IV, 11, n. 11

72. "Ipsum vero verbum Dei, ex hoc ipso quod est Deus intellectus, est verus Deus, habens naturaliter esse divinum: eo quod non est aliud naturale esse Dei et aliud eius intelligere, ut dictum est. Hinc est quod loan. 1-1 dicitur: Deus erat verbum". SCG. IV, 11, n. 11.

73. "lam enim ex dictis patet quod in Deo generationem intelligibilem ponimus, non autem talem qualis est in materialibus rebus, quarum generatio mutatio quaedam est, corruptioni opposita: quia neque verbum in intellectu nostro cum aliqua mutatione concipitur, neque habet oppositam corruptionem; cui quidem conceptioni similem esse filii Dei generationem, iam patet ex dictis". SCG. IV, 14, n. 2

74. CANALS VIDAL 2004, p. 340

75. "Similiter etiam verbum quod in mente nostra concipitur, non exit de potentia in actum nisi quatenus intellectus noster procedit de potentia in actum. Nec tamen verbum oritur ex intellectu nostro nisi prout existit in actu: simul autem cum in actu existit, est in eo verbum conceptum. Intellectus autem divinus nunquam est in potentia, sed solum in actu ut supra ostensum est. Generatio igitur verbi ipsius non est secundum exitum de potentia in actum: sed sicut oritur actus ex actu, ut splendor ex luce, et ratio intellecta ex intellectu in actu. Unde etiam apparet quod generatio non prohibet Dei filium esse verum Deum, aut ipsum esse aeternum. Quin magis necesse est ipsum esse coaeternum Deo, cuius est verbum: quia intellectus in actu nunquam est sine verbo". SCG. IV, 14, n. 3.

76. "Conceptio autem et partus intelligibilis verbi non est cum motu, nec cum successione: unde simul dum concipitur, est; et simul dum parturitur, distinctum est; sicut quod illuminatur, simul dum illuminatur, illuminatum est, eo quod in illuminatione successio nulla est. Et cum hoc inveniatur in intelligibili verbo nostro, multo magis competit verbo Dei: non solum quia intelligibilis conceptio et partus est; sed quia in aeternitate existit utrumque, in qua prius et posterius esse non possunt. Hinc est quod, postquam ex ore sapientiae dictum est, ante colles ego parturiebar; ne intelligeretur quod, dum parturiretur, non esset, subditur: quando praeparabat caelos, aderam". SCG. IV, 11, n. 18. 
de una nueva forma, que a su vez supone la estructura subyacente de potencia y acto y que no es otra cosa sino "la mutación del no ser al ser" ${ }^{\prime 77}$. Este sentido del cambio en el orden de los seres móviles, que en cuanto tales están ordenados a adquirir o perder determinadas perfecciones es el sentido más manifiesto de la noción de generación, pues está al alcance de nuestra condición hilemórfica ${ }^{78}$. Pero hay un segundo modo de entender la generación por el cual aplicamos dicha noción al movimiento de los vivientes y que se llama nacimiento en cuanto que es acción de un principio vital. Sto. Tomás explica que, en este sentido, la generación "significa el origen de un ser vivo que proviene de un principio viviente con el cual está unido"79. Sin embargo, esta definición es algo genérica y debe especificarse algo más, por ello, el Aquinate afirma que no cualquier ser que proviene de otro es su hijo, sino aquel que procede "según semejanza", y esto supone por el hecho que lo engendrado y su progenitor tienen la misma naturaleza específica, y es la manera como el hombre procede del hombre y el caballo del caballo ${ }^{80}$.

"Así pues, la procesión del Verbo en la divinidad dice razón de generación. Pues procede por modo de acción inteligible, que es operación vital, y según la razón de semejanza porque la concepción del intelecto es semejanza de la cosa entendida. Y procede en la misma naturaleza existente porque en Dios son lo mismo el ser y el entender. Por eso, la procesión del Verbo en Dios se llama generación y el mismo Verbo procedente se llama Hijo"81.

Santo Tomás afirma en este texto que la procesión del Verbo divino dice razón propia de generación, ya que es operación intelectual, que es una operación vital; en segundo lugar, tal acción dice razón de semejanza, pues quien procede es semejante a aquel de quien procede y es similar a él en la misma naturaleza específica. Para la generación es esencial que el generado y el generante posean la misma naturaleza idéntica esencialmente $^{82}$. De esta manera, el Verbo es aquel que procede de otro bajo la razón de semejanza específica. Ahora bien, es el mismo Aquinate quien se plantea la duda si por el hecho de que el Hijo reciba del Padre la generación no se estaría introduciendo una desproporción en la naturaleza del Hijo. Sto. Tomás enseña que la expresión 〈recibir» no implica desigualdad de naturaleza, sino sólo la relación del engendrado al Padre. Ya que el Hijo no es menor al Padre por el hecho que reciba tal naturaleza por generación inteligible. Se cumpliría tal cosa si tal generación estuviese sometida a las condiciones de la materialidad y potencialidad, cuyos cambios y movimientos suponen un sujeto permanente y receptivo de tales cambios.

"No todo lo aceptado es recibido en algún sujeto, de lo contrario, no podría decirse que toda la substancia de la cosa sea recibida por Dios, ya que toda la substancia no es un sujeto receptivo. Así de este modo, aquel que es engendrado en la divinidad recibe el ser del generante, pero no como si aquel ser sea recibido en una materia o un sujeto (lo que repugna la subsistencia del ser divino). Sino que se dice que es recibido en cuanto que procede de otro de quien tiene el ser divino y no como distinto del ser divino. Pues en la misma perfección del ser divino están contenidos el verbo que procede inteligiblemente y el principio del verbo, igual como todo lo que pertenece a su perfección" 83 .

Como la generación divina no es de orden material entonces no debe entenderse que el Verbo divino recibe su naturaleza como una parte que se origina en la otra parte desde donde efluye o nace. Como la procesión divina del Verbo es por modo inteligible excluye de su naturaleza cualquier elemento potencial y material. De esta manera el Verbo en la divinidad procede "de modo íntimo y sin diversidad, por modo inteligible" ${ }^{84}$. Según el Aquinate, los arrianos y sabelianos sostuvieron que la generación divina era de tipo material y potencial donde el que emana es distinto en naturaleza a aquel de quien procede y cuya operación es similar a la operación transitiva ${ }^{85}$. Así Arrio, apoyándose en textos bíblicos, sostuvo que "el Hijo de Dios era una criatura" que salió del Padre en desigualdad de naturaleza ${ }^{86}$. Por ello, continúa Sto. Tomás, aquellos textos bíblicos donde se dice del Hijo que 〈recibió〉 del Padre, por ejemplo, la glorificación (Juan 17, 5), deben ser entendidos de la comunicación de la naturaleza divina que se hace por medio del acto intelectual y de la relación subsiguiente a esa comunicación de naturaleza. Igualmente, sí el Verbo es llamado sabiduría y engendrada (Proverbios 8, 24. 25), no se está insinuando

77. S. Th. I, q. 27, a. 2. Cf. S. Th. 1, q. 44, a. 1, ad 2. Obviamente en la noción de movimiento como el acto del móvil es imprescindible incluir la noción de causa eficiente y final, pues el movimiento es el mismo ser del ente.

78. Por ello, enseña el Aquinate que el nombre de generación que usamos para aplicar a Dios se dice primero de Dios que, de las criaturas en cuanto a la realidad significada, pero no en cuanto al modo de significar porque en este caso se dice primero de las realidades creadas. Cf. S. Th. I, q. 34, a. 2, ad 4.

79. S. Th. I, q. 27, a.2.

80. Hablando de la semejanza y diferencia entre el hombre y el ángel el Aquinate afirma que el ángel es superior al hombre por su naturaleza estrictamente intelectual, pero que el hombre es superior al ángel porque el hombre por medio de la generación se parece más a Dios, ya que el ángel no genera otro ser semejante a si mismo. Cf. S. Th. I, q. 93, a. 3. Cf. MARTÍNEZ 2012, pp. 419-427; CANALS VIDAL 2004, pp. $279-288$.

81. "Sic igitur processio verbi in divinis habet rationem generationis. Procedit enim per modum intelligibilis actionis, quae est operatio vitae, et a principio coniuncto, ut supra iam dictum est, et secundum rationem similitudinis, quia conceptio intellectus est similitudo rei intellectae, et in eadem natura existens, quia in Deo idem est intelligere et esse, ut supra ostensum est. Unde processio verbi in divinis dicitur generatio, et ipsum verbum procedens dicitur filius". S. Th. I, q. 27, a.2.

82. En la divinidad este generado que tiene la misma naturaleza especifica que su generador dice razón de verbo, que en el ámbito creado no es subsistente y por lo mismo no dice razón de engendrado ni de hijo. Cf. S. Th. I, q. 33, a. 2, ad 2. Pues en nosotros como no son lo mismo el ser y en entender "el ser inteligible no tiene nuestra naturaleza". S. Th. I, q. 34, a. 2, ad 1, ni tampoco la naturaleza de hijo. Pues el que generante genera algo similar a sí mismo según la razón de especie, pero no según las propiedades individuales. Cf. De Potentia q. 9, a. 5, ad 18.

83. S. Th. I, q. 27, a. 2, ad 3.

84. S. Th. I, q. 27, a. 1, ad 3.

85. Por ello, para Arrio entre el Padre y el Hijo existe diversidad de substancias, y por ello, al Hijo no se le da el nombre propio de Verbo, sino sólo en sentido metafórico. Cf. S. Th. I, q, 34, a. 1, ad 1.

86. Las fuentes doctrinales de Arrio según el Aquinate se encuentran en la teología del alejandrino Orígenes. Cf. S. Th. I, q. 34, a. 1, ad 1. 
desigualdad de naturaleza, sino que por la generación inteligible "Io que se engendra recibe la naturaleza del engendrante, lo que es una perfección. Pero en la generación que es entre nosotros, el generante mismo se muda, lo que es una imperfección" ${ }^{87}$. Pero en la generación del Verbo no hay uno que da y otro que reciba en sentido material, sino que su totalidad se origina en el otro y, por ello, no hay que asignar un recipiente y un recibido.

\begin{abstract}
"Pero en la generación intelectual no sucede así. Pues el verbo no se origina del intelecto de tal modo que una parte se entienda como recipiente, y que otra parte efluya del intelecto, sino que todo el verbo tiene su origen del intelecto. Como en nosotros un verbo totalmente de otro se origina, igual como la conclusión desde los principios. Y donde una cosa en su totalidad de otro se origina no hay que asignar un recipiente y un recibido, sino que todo lo que se origina de él es de quien procede" ${ }^{\prime 88}$.
\end{abstract}

Si el modo de comunicar la naturaleza divina poseyera las propiedades que encontramos en los cuerpos donde por la concurrencia de los progenitores una parte de ellos origina numéricamente un nuevo ser vivo entonces una parte de la substancia del Padre se comunicaría al Hijo. Ahora bien, en la generación del Hijo el Padre comunica toda su naturaleza, pero no de modo material, sino por comunicación inteligible, pues Dios al entenderse toda su plenitud estará también en el Verbo.

"Y porque la generación del Hijo no es material, sino inteligible es una estulticia plantear si el Padre dio toda la naturaleza al Hijo o una parte. Ya que es manifiesto que si Dios se entiende es necesario que toda su plenitud se contenga en el Verbo. Y tampoco la substancia dada al Hijo deja de estar en el Padre porque tampoco en nosotros deja de estar la propia naturaleza de la cosa que se entiende, por esto, que nuestro verbo intelectual por la misma realidad entendida contenga la misma naturaleza inteligiblemente" ${ }^{\prime \prime 9}$.
En virtud de esta comunicación de la naturaleza por operación inteligible el Hijo es consubstancial con el principio de donde procede, "pues cuando se dice que el Hijo ha nacido «del Padre), esta preposición ¿de` indica el principio generador consubstancial y no principio material" 90 . Ahora bien, este modo de comunicar la naturaleza por medio de generación es proporcionado a la perfección del ser, que por su propia naturaleza es comunicativo. Ya que el entender es perfección que se sigue de la posesión íntima del acto de ser por parte del sujeto que genera el verbo y pertenece a la perfección del entender proferir un verbo que semejante a aquel de quien brota. Ya que el obrar propio de un agente es obrar comunicando aquello que es en acto. De esta manera, la generación del ser es la manifestación de la misma plenitud entitativa del agente generante.

\begin{abstract}
"Hay que decir que la naturaleza de cualquier acto es que a sí mismo se comunique en cuanto le es posible. Por eso, cada agente obra según que está en acto. Pues el obrar no es sino comunicar aquello por lo que el agente está en acto según que le es posible. Ahora bien, la naturaleza divina es máxima y puramente acto. Por eso, ella misma se comunica cuanto le es posible. Y se comunica a sí misma por la semejanza de las criaturas, como es a todos patente, ya que cualquier criatura es ente según la semejanza a ella. Pero la fe católica sostiene que hay otro modo de comunicación en cuanto que la misma se comunica con comunicación en cierto modo natural. Tal como aquel a quien se comunica la humanidad es el hombre; así también aquel a quien se le comunica la deidad no sólo es similar a Dios, sino verdadero Dios" ${ }^{\prime 1}$.
\end{abstract}

Para Sto. Tomás la acción generativa es acción vital que procede de un agente en acto y que como tal obra en virtud de la actualidad que posee. De este modo, la generación es acción de un agente en acto que por su naturaleza es comunicativo y difusivo. En el texto citado se nombra la generación del Verbo como una "comunicación en cierto modo natural", que se identifica con la comunicación inteligible de la naturaleza divina ${ }^{92}$ y agrega que "de esta manera esta comunicación

87. "Quod autem dicitur sapientia esse creata primo quidem, potest intelligi, non de sapientia quae est filius Dei, sed de sapientia quam Deus indidit creaturis. Dicitur enim Eccli. 1-9, ipse creavit eam, scilicet sapientiam, spiritu sancto, et effudit illam super omnia opera sua. Potest etiam referri ad naturam creatam assumptam a filio: ut sit sensus, ab initio et ante saecula creata sum, idest, praevisa sum creaturae uniri. Vel, per hoc quod sapientia et creata et genita nuncupatur, modus divinae generationis nobis insinuatur. In generatione enim quod generatur accipit naturam generantis, quod perfectionis est: sed in generationibus quae sunt apud nos, generans ipse mutatur, quod imperfectionis est. In creatione vero creans non mutatur, sed creatum non recipit naturam creantis. Dicitur ergo simul filius creatus et genitus, ut ex creatione accipiatur immutabilitas patris, et ex generatione unitas naturae in patre et filio. Et sic huiusmodi Scripturae intellectum synodus exposuit: ut per Hilarium patet". SCG IV. 8, n. 10.

88. "Ex hoc etiam quod divina generatio non est materialis, manifestum est quod non oportet in filio Dei esse aliud recipiens, et aliud naturam receptam. Hoc enim in materialibus generationibus accidere necesse est inquantum materia generati recipit formam generantis. In generatione autem intelligibili non sic est. Non enim sic verbum ab intellectu exoritur quod pars eius praeintelligatur ut recipiens, et pars eius ab intellectu effluat, sed totaliter verbum ab intellectu originem habet: sicut et in nobis totaliter unum verbum ex aliis oritur, ut conclusio ex principiis. Ubi autem totaliter aliquid ex alio oritur, non est assignare recipiens et receptum, sed totum quod exoritur ab eo est a quo oritur". SCG. IV. 14, n. 5.

89. SCG IV, 14, n. 4,

90. S. Th. I, q. 41, a. 3, ad 1. Enseña Sto. Tomás que la preposición <de〉 siempre indica la consubstancialidad y en este sentido se dice que el Hijo es engendrado de la esencia del Padre porque la esencia del Padre es comunicada al Hijo por generación inteligible. Cf. S. Th. l, q. 41, a. 3, ad 2.

91. "Dicendum, quod natura cuiuslibet actus est, quod seipsum communicet quantum possibile est. Unde unumquodque agens agit secundum quod in actu est. Agere vero nihil aliud est quam communicare illud per quod agens est actu, secundum quod est possibile. Natura autem divina maxime et purissime actus est. Unde et ipsa seipsam communicat quantum possibile est. Communicat autem se ipsam per solam similitudinem creaturis, quod omnibus patet; nam quaelibet creatura est ens secundum similitudinem ad ipsam. Sed fides Catholica etiam alium modum communicationis ipsius ponit, prout ipsamet communicatur communicatione quasi naturali: ut sicut ille cui communicatur humanitas, est homo, ita ille cui communicatur deitas, non solum sit Deo similis, sed vere sit Deus". De Potentia, q. 2, a. 1.

92. La misma comunicación inteligible de la naturaleza por la cual se engendra un verbo interior se puede llamar natural pues las concepciones inteligibles se reducen a ciertos principios naturalmente conocidos. Como Dios se entiende a sí mismo naturalmente su concepción del Verbo es natural. Cf. S. Th. I, q. 41, a. 2, ad 4 . 
que se hace de modo inteligible también se hace de modo natural"93. Este modo de comunicar inteligiblemente la naturaleza es lo que propiamente se denomina generación en Dios, por la cual "todo el que por su acción produce algo similar a sí mismo en cuanto a la forma por la que obra como el hombre engendrado es similar en la naturaleza humana al que le engendró, por cuya virtud un padre puede engendrar un hombre. Luego, aquello que es potencia generativa en algún generante es aquello por lo que el generado se asemeja al que le engendró. Por ello, el Hijo se asemeja al Padre que le engendra en la naturaleza divina" 94 . Y de esta manera es "el mismo Hijo subsistente quien posee la naturaleza divina" ${ }^{95}$.

Por ello enseña el Aquinate que este modo de concebir del Padre al Verbo es por modo de naturaleza y de ningún modo por la voluntad. Ya que concebir la generación del Verbo por modo de voluntad es propio del error arriano. "Por eso, los arrianos queriendo deducir que el Hijo es criatura dijeron que el Padre engendró al Hijo por voluntad según que la voluntad designa el principio. Sin embargo, nosotros decimos que el Padre engendró al Hijo no por voluntad, sino por naturaleza" ${ }^{96}$.

\section{LA PERSONA DEL VERBO}

Santo Tomás enseña en la Suma de Teología que el nombre de Verbo es nombre personal y de ningún modo nombre solamente esencial. Y lo muestra aclarando los sentidos que en nosotros tiene el nombre de verbo. Verbo se puede tomar en primer término en sentido metafórico cuando se usa para expresar lo que se expresa o hace de palabra. Pero el término verbo tiene tres sentidos propios, el primero de los cuales es cuando significa lo que profieren los labios, que es una palabra que proviene de la interioridad en cuanto a la voz y el significado de esa palabra. Ya que la palabra significa lo que el entendimiento entendiendo concibe y que procede de la imaginación, por lo tanto, en este sentido, la palabra es la expresión exterior de aquello que primero concibió la inteligencia. Sin embargo, de una manera propia y principal se llama verbo "al concepto interior de la mente" ${ }^{97}$, en segundo, lugar a la palabra o voz exterior que es la expresión vocal y en tercer lugar a la misma imagen de la voz ${ }^{98}$.
"Se llama propiamente verbo en Dios en cuanto que significa el concepto del intelecto. Por ello Agustín dice, en el libro XV de la Trinidad: Cualquiera que pueda entender el verbo, no sólo antes que resuene, sino también antes que el sonido se engarce en la imaginación de la palabra, ya se puede ver alguna semejanza del Verbo del cual se dijo, en el principio era el Verbo. Ahora bien, es de la razón de concepto del corazón que proceda de otro, a saber, de la noticia del concipiente. Por eso, el Verbo que propiamente se dice en la divinidad significa algo de otro procedente, que pertenece a la razón de los nombres personales en la divinidad, ya que las personas divinas se distinguen por el origen. Por eso, es necesario que el nombre de verbo según que se toma propiamente en la divinidad, no se toma en sentido esencial, sino sólo personal" ${ }^{99}$.

Santo Tomás es claro en afirmar que lo que procede según el concepto inteligible y semejanza, y en virtud de la cual se establece la identidad entre lo conocido y cognoscente, es nombre personal y de ningún modo un nombre que pertenezca a toda la esencia. Si Verbo en la divinidad fuera un nombre de la esencia no habría modo de distinguir las personas, ya que éstas se distinguen por sus relaciones reales de origen, que suponen no sólo un proceder el uno del otro, sino que son actos inmanentes distintos. Debemos consignar que el Aquinate al comienzo de su carrera docente en el Comentario a las Sentencias se mantuvo dubitativo en este punto, pues afirmó que el nombre de Verbo era tanto un nombre esencial como personal. "Algunos dicen que el nombre de verbo siempre es personal, pero esto no parece ser verdadero" ${ }^{100}$. En la cuestión disputada De Veritate (1254-1256), explicita la dificultad que tiene este tema. Dice que aparentemente esta cuestión es simple, pero si la consideramos detenidamente aparece en toda su complejidad. La dificultad está en que tanto la operación de entender como el verbo interior tienen un origen o procedencia, y, por ende, se debe delimitar claramente sus naturalezas. Así nos relata en De Veritate la dificultad que conlleva esta cuestión.

“Pero considerada más profundamente se encuentra que es difícil,
ya que en la divinidad encontramos algo que incluye el origen, no
según la realidad, sino sólo según la razón. Como este nombre
operación, que sin ninguna duda incluye algo procedente del ope-
rante; sin embargo, este proceso no es sino sólo según la razón.
Por eso, esta operación en la divinidad se dice esencialmente y no

93. De Potentia, q. 2, a. 1. Cf. De Potentia q. 2, a. 3.

94. S. Th. I, q. 41, a. 5.

95. De Potentia, q. 2, a. 1, ad 2. Y por lo mismo no hay desigualdad de naturaleza entre el Padre y el Hijo, pues si así fuera no poseerían la misma esencia. Cf. S. Th. I, q. 42, a. 1.

96. S. Th. I, q. 41, a. 3.

97. "Dicitur autem proprie verbum in Deo, secundum quod verbum significat conceptum intellectus. Unde Augustinus dicit, in XV de Trin., quisquis potest intelligere verbum, non solum antequam sonet, verum etiam antequam sonorum eius imagines cogitatione involvantur, iam potest videre aliquam verbi illius similitudinem, de quo dictum est, in principio erat verbum. Ipse autem conceptus cordis de ratione sua habet quod ab alio procedat, scilicet a notitia concipientis. Unde verbum, secundum quod proprie dicitur in divinis, significat aliquid ab alio procedens, quod pertinet ad rationem nominum personalium in divinis, eo quod personae divinae distinguuntur secundum originem, ut dictum est. Unde oportet quod nomen verbi, secundum quod proprie in divinis accipitur, non sumatur essentialiter, sed personalite". S. Th. I, q. 34, a. 1.

98. "Ad primum igitur dicendum, quod quamvis nomen verbi impositum sit a motu corporali, quod est ultimum in nostra locutione; tamen impositum est ad significandum omne quod dicitur vel exterius vel interius". In I Sent. d. 27, q. 2, a. 1, ad 1.

99. S. Th. I, q. 34, a. 1.

100. "Unde dicunt, quod verbum dictum de Deo semper est personale. Sed hoc non videtur verum". In I Sent. d. 27, q. 2, a. 2, qc 1 co. 
personalmente. Porque en Dios no difieren la esencia, la potencia y la operación. Por ello, no es inmediatamente evidente si este nombre verbo incluya un proceso real como este nombre hijo o sólo de razón como este nombre operación, y de esta manera si se dice esencial o personalmente" 101.

En este texto vislumbra la dificultad del asunto, pero todavía no es clara la solución y salida de esta objeción. Pues "no es inmediatamente evidente si este nombre verbo" es fruto de la acción de entender común a toda la divinidad o pertenece a la acción por la cual se profiere el verbo mental. En De Veritate mantiene la misma actitud dubitativa del Comentario a las Sentencias. La maduración en la naturaleza de esta doctrina por parte de Sto. Tomás debe entenderse no sólo como expresión de la natural debilidad y finitud del entendimiento humano, sino también de su actitud de hacer teología como tarea al servicio del dato revelado. Por ello, retrocedamos hasta el texto del Comentario a las Sentencias donde el verbo es tomado, ya sea como el acto de entender o como la misma especie que es semejanza de la cosa entendida.

“Porque si alguien investigue qué es este verbo por el cual alguien para sí habla no encontrará que no es, sino la concepción del intelecto. Pues la concepción del intelecto o es la misma operación que es el entender o la especie entendida. Por eso, es necesario que el verbo se diga o de la misma operación de entender o de la misma especie que es semejanza de la cosa entendida. Y sin ninguno de estos nadie puede entender. Pues ninguno de estos es por lo que alguien formalmente entiende. Y por eso, es imposible que tomando de este modo el verbo alguien entienda sino por su verbo intelectual, que sea su operación o la razón de su operación considerada como el medio de conocer que es la especie de la cosa conocida. Por ello, como el Padre se entienda a sí mismo si no hubiese allí sino un verbo personal, que es el Hijo, es necesario que el Padre entendiera al Hijo casi formalmente, y esto se ha demostrado como improbable en la disputación 5, q. 3, a. 1. Y por eso, hay que decir, con algunos, que este nombre verbo en virtud del vocablo puede decirse personal y esencialmente" ${ }^{102}$.

El Aquinate sostiene que la noción de verbo en la divinidad puede entenderse ya sea como nombre personal como nombre esencial. La dificultad que movió al Aquinate, como él mismo ha relatado en De Veritate, ha sido que no ha visto cómo distinguir adecuadamente el acto de entender por el cual la divinidad se entiende a sí misma del acto por el cual procede el verbo: pues el acto de entender no dice razón de procesión de origen, sino que es acto de la esencia divina. El acto de entender dice, el Aquinate, "no significa sólo la relación, como este nombre Padre o Hijo, sino que se ha impuesto para significar alguna realidad absoluta con respecto, como este nombre ciencia, que no es relación de origen, según que es referida la ciencia a aquello por lo cual es. Sino que es relación según que se refiere a aquello a lo cual es, a saber, lo escible. En cambio, este nombre verbo incluye la relación según que se refiere a aquello de lo cual es, a saber, el discente"103. Para el Aquinate la relación que se origina por la acción de entender es relación de razón, pues es acción común a toda la divinidad, en cambio la noción de verbo incluye la referencia real a quien lo dice y es una relación real ${ }^{104}$. Por eso, si la relación que incluye el nombre verbo es sólo una relación de razón entonces el verbo se dirá esencialmente en la divinidad y esto parece que es suficiente para la noción de verbo aplicada a Dios desde el concepto en nosotros existente. Ya que el verbo se puede entender como la especie entendida o la misma acción del inteligente y ninguno de éstos se distingue de la esencia divina. En cambio, si verbo incluye relación real es necesario que verbo se diga personalmente, ya que queda referido a aquel de quien procede ${ }^{105}$.

101. "Sed, interius considerata, difficilior invenitur, eo quod in divinis invenimus quaedam quae originem important non secundum rem, sed secundum rationem tantum; sicut hoc nomen operatio, quae proculdubio importat aliquid procedens ab operante: et tamen iste processus non est nisi secundum rationem tantum; unde operatio in divinis non personaliter, sed essentialiter dicitur, quia in Deo non differt essentia, virtus et operatio. Unde non statim fit evidens, utrum hoc nomen verbum processum realem importet, sicut hoc nomen filius; vel rationis tantum, sicut hoc nomen operatio; et ita utrum personaliter vel essentialiter dicatur". De Veritate q. 4, a. 2.

102. "Quia si inquiratur quid sit istud verbum quo aliquis sibi loquitur, non invenitur esse nisi conceptio intellectus. Conceptio autem intellectus est vel operatio ipsa quae est intelligere, vel species intellecta. Unde oportet quod verbum vel dicatur ipsa operatio intelligendi, vel ipsa species quae est similitudo rei intellectae; et sine utroque istorum non potest quis intelligere: utrumque enim istorum est id quo quis intelligit formaliter. Et ideo impossibile est quod accipiendo hoc modo verbum, aliquis intelligat nisi verbo intellectus sui, quod sit vel operatio ejus, vel ratio operationis ad eam, sicut medium cognoscendi se habens, quae est species rei intellectae. Unde cum pater intelligat se, si non esset ibi nisi verbum personale, quod est filius, oporteret quod pater intelligeret filio, quasi formaliter: et hoc supra improbatum est, dist. 5, quaest. 3, art. 1. Et ideo dicendum est cum aliis, quod hoc nomen verbum ex virtute vocabuli potest personaliter et essentialiter accipi". In I Sent. d. 27, q. 2, a. 2, qc 1 co.

103. "Non enim significat tantum relationem, sicut hoc nomen pater, vel filius, sed imponitur ad significandum rem aliquam absolutam simul cum respectu, sicut hoc nomen scientia; sed in hoc differt, quia relatio quae importatur hoc nomine scientia, non est relatio originis, secundum quam referatur scientia ad illud a quo est; sed est relatio secundum quam refertur ad illud ad quod est, scilicet ad scibile; sed hoc nomen verbum importat relationem secundum quam refertur ad illud a quo est, scilicet ad dicentem". In I Sent. d. 27, q. 2, a. 2, qc 1 co. Sobre la distinción entre decir y entender ver S. Th. I, q. 34, a. 1, ad 2 et 3; De Veritate q. 4, a. 2, ad 4 et 5.

104. "Hujusmodi autem relationes in divinis contingit esse dupliciter: quaedam enim sunt reales, quae requirunt distinctionem realem, sicut paternitas et filiatio, quia nulla res potest esse pater et filius respectu ejusdem; quaedam autem sunt relationes rationis tantum, quae non requirunt distinctionem realem, sed rationis, sicut relatio quae importatur in hoc nomine operatio". In I Sent. d. 27, q. 2, a. 2, qc 1 co.

105. "Si igitur relatio importata hoc nomine verbum, sit relatio rationis tantum, sic nihil prohibet quin essentialiter dicatur, et videtur sufficere ad rationem verbi, secundum quod a nobis in Deum transumitur; quia in nobis, ut dictum est, art. praec., nihil aliud est verbum nisi species intellecta, vel forte ipsa operatio intelligentis: et neutrum eorum realiter distinguitur ab essentia divina. Si autem importet relationem realem distinctionem exigentem, oportet quod personaliter dicatur, quia non est distinctio realis in divinis nisi personarum". In I Sent. d. 27, q. 2, a. 2, qc 1 co. De igual modo ocurre en la formación del verbo interior en el intelecto creado por el cual se establece una relación de razón en aquellas operaciones que son del intelecto, pero cuando el acto cognoscitivo forma y concibe un verbo se establece una relación real entre el acto cognoscitivo y la cosa conocida. Cf. MOYA 2013, pp. 123-124. 
Para el Aquinate verbo en la divinidad puede tomarse ya sea como aquello por lo que formalmente la divinidad entiende y de este modo se identifica con la misma esencia divina (o la especie inteligible en nosotros), y así será la misma esencia la que se manifiesta como verbo y entre ambos no hay sino una distinción de razón, como difieren el que entiende, aquello por lo que entiende y lo entendido ${ }^{106}$. De esta manera es la misma noticia y no se dice propiamente verbo o aquello por lo que se conoce y este concepto siempre se dirá esencialmente de la divinidad igual como sabiduría u otros similares, y por ello, nombra algo no realmente distinto de la esencia divina ${ }^{107}$. Pero tanto en la Suma de Teología como en la Suma contra Gentiles, de forma definitiva, afirmará que verbo se dice personalmente. Y lo mismo ocurre con la procesión del amor ${ }^{108}$. Pues la dificultad de no distinguir entre ambos modos de concebir el verbo está en que el verbo no se distinguiría realmente de la esencia divina ${ }^{109}$. Por eso, escribe en la Suma de Teología dando un paso definitivo en su profundización de la Revelación distingue entre las nociones de entender y decir:

"Así pues a una persona en la divinidad conviene decirse del modo por el que se dice el Verbo. En cambio, ser dicho por el modo como se entienden las cosas en el Verbo conviene a cada una de las personas divinas... Pues entender incluye la sola relación del inteligente a la cosa entendida en la cual ninguna razón de origen se incluye, sino sólo la información en el intelecto nuestro en cuanto que nuestro intelecto se hace en acto por la forma de la cosa conocida. Pero decir, incluye principalmente relación al verbo concebido, pues decir, no es otra cosa sino proferir un verbo. Pero mediante el verbo se incluye la relación a la realidad entendida que se manifiesta en el verbo prolado al inteligente. Así pues, por la sola persona que profiere el Verbo hay un dicente en la divinidad, no obstante, cada una de las personas entiende y es entendida, y, por ende, dicha en el Verbo" 110.

De esta manera, el Aquinate justifica que el Verbo es propiamente un nombre personal que procede según generación inteligible en virtud de la razón de semejanza específica y fundado en la identidad en Dios del ser y el entender que es expresión de la misma vida divina. En cambio, en la acción de entender en Dios no se incluye razón de origen real, sino solo a la realidad conocida. Por eso, en la Suma de Teología enseña que el Verbo engendrado en Dios es realidad personal y que procede como algo subsistente y en el ser hipostático distinto realmente de quien procede.

“En nosotros no es lo mismo el ser y el entender, por eso, aquello que en nosotros tiene el ser inteligible no pertenece a nuestra naturaleza. Pero el ser de Dios es su mismo entender, por eso, el Verbo de Dios no es algún accidente o algún efecto de Él, sino que tiene su misma naturaleza. Y por eso, es necesario que sea

106. "Ad quartum dicendum, quod intellectus divinus non intelligit essentiam suam per aliquam speciem differentem essentialiter aut realiter ab ipsa essentia; nihilominus tamen ipse intelligit essentiam suam per essentiam suam; unde essentia se habet ut intelligens et ut intellecta et ut quo intelligitur; et inquantum se habet ut intelligens, sic vere et proprie est ibi ratio intellectus; et inquantum se habet ut id quod intelligitur, est ibi vere ratio intellecti; sed inquantum se habet ut quo intelligitur, sic est ibi ratio verbi". In I Sent. d. 27 q. 2 a. 1 ad 4.

107. "Ad primum igitur dicendum, quod notitia non dicit totam rationem verbi: quia notitia et sapientia dicuntur per modum quiescentis et manentis in eo cujus sunt; et ideo nunquam dicuntur nisi essentialiter, quamvis possint esse appropriata: sed verbum dicit quamdam emanationem intellectus, et exitum in manifestationem sui; et ideo, quia exitus iste potest intelligi vel secundum rem distinctam, prout filius exit a patre, vel secundum rationem tantum, prout intelligere est ab intellectu divino; ideo verbum quandoque essentialiter et quandoque personaliter dicitur, sicut et amor". In I Sent. d. 27 q. 2 a. 2 , qc 1, ad 1. Esta distinción que hace en este texto el Aquinate también se encuentra en la Suma de Teología, donde escribió que decir es propiedad del Padre de quien procede como dicho el Hijo, en cambio, entender es propiedad común de las tres personas divinas. Cf. S. Th. I, q. 34, a. 1, ad 3. Sobre esta distinción desarrollada por Jon Poinsot en sus comentarios a la Suma de Teología ver Joannes a Sancto Thoma. In I STh, q. 27, D. 32, a. 5, nn. 27, 28 y 31.

108. "Et est simile de amore, qui secundum eamdem distinctionem essentialiter et personaliter dicitur, ut supra dictum est, dist. 18, quaest. 1, art. 1. Cum enim verbum sit similitudo ipsius rei intellectae, prout est concepta in intellectu, et ordinata ad manifestationem, vel ad se, vel ad alterum; ista species in divinis potest accipi dupliciter: vel secundum quod dicit id quo aliquid formaliter in divinis intelligitur; et sic, cum ipsa essentia per se intelligatur et manifestetur, ipsa essentia erit verbum; et sic verbum et intellectus et res cujus est verbum, non differunt nisi secundum rationem, sicut in divinis differunt quo intelligitur et quod intelligitur et quod intelligit; vel secundum quod species intellecta nominat aliquid distinctum realiter ab eo cujus similitudinem gerit; et sic verbum dicitur personaliter, et convenit filio, in quo manifestatur pater, sicut principium manifestatur in eo quod est a principio per modum intellectus procedens. Sed tamen in usu sanctorum et communiter loquentium est quod hoc nomen verbum relationem realiter distinguentem importat, ut dicit Augustinus, quod verbum idem est quod sapientia genita; et ideo ista quaestio parum valet, quia non est de re, sed de vocis significatione, quae est ad placitum; unde in ea plurimum valet usus, quia nominibus utendum est ut plures, secundum philosophum; de rebus autem judicandum secundum sapientes. Cum enim de rebus constat, frustra in verbis habetur controversia, ut dicit Magister, Lib. 2, dist. 14. Sed tamen ea quae in divinis dicuntur, non sunt extendenda nisi quantum sacra Scriptura eis utitur". In I Sent. d. 27, q. 2, a. 2, qc 1 co.

109. "Ad sextum dicendum, quod in divinis non est nisi tantum unum verbum; et tamen est ibi verbum personale et essentiale, quia persona non distinguitur ab essentia; unde nec excluditur per dictionem exclusivam". In I Sent. d. 27, q. 2, a. 2, qc 1, ad 6.

110. S. Th. I, q. 34, a. 1, ad 3. Tomás en este texto de la Suma afirma que el entender es acción común a toda la Trinidad, ya que el entender en Dios es esencial (S. Th. I, q. 34, a. 2, ad 4) y se identifica con el decir. Entender y decir señalan lo mismo, pero con una diferencia, pues en el decir se incluye la locutividad y manifestación del entender por medio del verbo, en cambio, entender expresa sólo la acción de entender, que es una cualidad. El decir es la acción que incluye la comunicatividad y fecundidad en acto del entendimiento. Pues, es el mismo conocimiento el que forma y concibe lo que conoce en un verbo. Advierte Canals que de esta distinción no se ha de concluir que el verbo mental es manifestado ex indigentia por la ausencia del objeto. Por medio de la acción de entender se forma el verbo en el que se entiende. Cf. CANALS VIDAL, sin año de edición, pp. 190-191, 548-549. 
algo subsistente porque todo lo que está en la naturaleza divina subsiste. Y por ello, el Damasceno dice que el Verbo de Dios es substancial y ente hipostático, mientras que los otros verbos, a saber, los nuestros, son virtudes del alma" ${ }^{111}$.

Como el entender en Dios no es un accidente de su substancia, sino que se identifica con su esencia, todo lo que emana de Él a modo de procesión inteligible posee el ser subsistente y, por ello, tiene un nombre propio y personal. Y con toda propiedad identificamos al Padre como origen del Hijo y al Hijo como originado por el Padre al pronunciarlo. Pues el Verbo originado del Padre es coesencial con el principio de donde procede ${ }^{112}$. Y con justa razón concluye el Aquinate que "hay que tener presente que el Verbo de Dios se diferencia de la idea que está en la mente del artífice porque el Verbo de Dios es subsistente; en cambio, la idea de la obra en la mente del artífice no es algo subsistente, sino sólo la forma inteligible" ${ }^{113}$.

\section{CONCLUSIÓN}

Damos por concluido el camino que comenzamos para reconstruir el pensamiento de Santo Tomás sobre el mayor misterio del cristianismo y que nos separa de las otras religiones reveladas. Hemos mostrado cómo para el Aquinate la verdad de la vida divina intratrinitaria es el misterio más insondable, pero no por ello obliga al cristiano a renunciar a su comprensión racional. En este sentido debe entenderse la opción filosófica que ha hecho el Aquinate por la metafísica de Aristóteles como instrumento de la concepción teológica. La opción por el Estagirita está más allá de una coyuntura histórica y supone una convicción por desentrañar la verdad revelada. Pero su estructura teológica quedaría incompleta sí no se considera el aporte de los Padres de la Iglesia, y en especial de San Agustín, en su original concepción de la Trinidad de personas y en específico de la procesión del Verbo.

El Aquinate sigue la intuición fundamental del genio hiponense de encontrar en la estructura del espíritu humano la vía de comprensión del misterio trinitario ${ }^{114}$, pues el hombre asciende a la inteligibilidad de lo divino desde lo que le es más manifiesto a su razón mediada por los sentidos ${ }^{115}$. El Aquinate descubre en la interioridad del espíritu humano la imagen de la Trinidad, que le permite no sólo comprender la espiritualidad insondable humana, sino también el misterio trinitario. En el interior del hombre habita la verdad que es el pivote para ascender a la comprensión de aquel Verbo eterno que procede en igualdad de semejanza y que a diferencia del verbo mental finito es subsistente. El Verbo eterno procede de la misma intimidad subsistente del Padre, cuya actualidad origina un verbo que es su propia imagen y que emana como el acto del acto y la luz de la luz en perfecta igualdad y semejanza. En cambio, el verbo finito que procede de la misma actualidad del espíritu no es perfecta semejanza de quien procede ni procede como subsistente, no obstante, procede como acto de acto y luz de luz, y de esta manera, aquella primera intuición de los pensadores cristianos llega a su culminación en la teología de Sto. Tomás. Por ello, Santo Tomás no duda en afirmar "que como el Hijo está en el Padre como Verbo de Él, no podría haber en el Padre pleno gozo de sí mismo sino en el Hijo, igual como el hombre no tiene gozo de si, sino por la concepción que de sí mismo tiene" ${ }^{116}$.

111. "Ad primum ergo dicendum quod in nobis non est idem esse et intelligere, unde illud quod habet in nobis esse intelligibile, non pertinet ad naturam nostram. Sed esse Dei est ipsum eius intelligere, unde verbum Dei non est aliquod accidens in ipso, vel aliquis effectus eius; sed pertinet ad ipsam naturam eius. Et ideo oportet quod sit aliquid subsistens, quia quidquid est in natura Dei, subsistit. Et ideo Damascenus dicit quod verbum Dei est substantiale, et in hypostasi ens, reliqua vero verba, scilicet nostra, virtutes sunt animae". S. Th. I, q. 34, a. 2, ad 1.

112. Cf. De Potentia q. 8, a. 1, ad 3.

113. "Sciendum tamen quod verbum Dei in hoc differt a ratione quae est in mente artificis, quia verbum Dei Deus subsistens est: ratio autem artificiati in mente artificis non est res subsistens, sed solum intelligibilis forma". SCG IV, 13, n. 9.

114. "Dico ergo, quod verbum in divinis dicitur ad similitudinem nostri verbi, ratione impositionis nominis, non propter ordinem rei. De Veritate q. 4, a. 1, ad 10.

115. Cf. S. Th. I, q. 84, a. 7.

116. De Potentia q. 9, a. 5, ad 24. 
BIBLIOGRAFÍA

- AAVV. Verbo de Dios y palabras humanas. En el XVI Centenario de la conversión cristiana de San Agustín, Ediciones de la Universidad de Navarra, Pamplona, 1988.

- Aristóteles. Acerca del Alma, Gredos, Madrid, 1998, Traducción de T. Calvo Martínez.

- Aquino, Santo Tomás. Summa Theologica, BAC, Madrid, 1985, 5 volúmenes.

- Suma Contra los Gentiles, BAC, Madrid, 1968, 2 volúmenes.

- Super Evangelium S. loannis lectura, Marietti, Taurini-Romae, 1952. A cura P. Raphaelis Cai O. P.

- - De Veritate. Cuestión 4. Acerca del Verbo, Cuadernos de Anuario Filosófico 127, 1991. Introducción y traducción de María Jesús Soto Bruna

- Argüello, Santiago. "La polisemia del término potencia en la filosofía tomística de la mente" , Patristica et Mediaevalia, XXXV, $2014,15-30$.

- - "La lectura romana y la evolución de la enseñanza de Tomás de Aquino sobre la imagen y semejanza de Dios", Estudios Filosóficos, LXI, 2012, 245-276.

- - "Memoria, intelligentia et voluntas en Tomás de Aquino: la aportación de la lectura romana para su mejor comprensión", Studium, 2010, 11-33.

- Canals Vidal, Francisco. La esencia del conocimiento, PPU, Barcelona, 1987.

- Escritos filosóficos (I). Editorial Balmes, Barcelona, sin año de edición.

- - Cuestiones de Fundamentación, Publications i Edicions Universitat de Barcelona, Barcelona, 1987.

- -Tomás de Aquino. Un pensamiento siempre actual y renovador, Scire selecta, Barcelona, 2004.

- - "La palabra del hombre en la vida humana", Espíritu LIX, 2010, n. 140, 543.

- Cruz, Juan. “Emanación: un concepto neoplatónico en la metafísica de Tomás de Aquino", Anuario Filosófico, 2000 (XXXIII), 461-490.

- Forment, Eudaldo. Lecciones de metafísica, Rialp, Pamplona, 1992.

- Hernández, Francisco. "El criterio de cognoscibilidad en Tomàs de Aquino: entre la intencionalidad y la inmaterialidad", Revista de Humanidades n. 30, julio-diciembre, 2014, 11-27.

- García López, Jesús. "El conocimiento del yo según Santo Tomás", Anuario Filosófico, IV, 1971, 87-115, 2015, $25-42$.

- García Cuadrado, José Ángel. "Vivir es el ser de la persona: Una interpretación de la sustancia aristotélica", Comprendre, Vol 17/2,

- Izquierdo, César "La teología del Verbo en la Summa contra Gentiles", Scripta Theologica 14, 1982/2, 551-580.

- Juárez, Guillermo. "El tratado trinitario en Suma de teología de Tomás de Aquino", Scripta mediaevalia, 4, n. 2, 2011, 62-80.

- Martínez, Enrique. "Realismo pensante. La metafísica del conocimiento de Francisco Canals", Anuario filosófico, XLIII/3, $2010,471-476$.

- - "El entendimiento agente en Juan de Sto. Tomás", en J. F. SELLÉS (Ed), El intelecto agente en la escolástica renacentista, Eunsa, Colección Pensamiento Medieval y Renacentista, Pamplona, 2006, 301-314.

- Moya, Patricia. El conocimiento nuestro acceso al mundo. Cinco estudios de filosofía del conocimiento, Editorial Universitaria, Santiago, 2013.

- - "La dimensión manifestativa del concepto", Pensamiento, vol., 68, n. 255, 2012, 79-106.

- - "Inmanencia, intencionalidad y representación según Tomás de Aquino", Veritas 28, 2013, $113-131$.

- Orbe, Antonio. Hacia la primera teología de la procesión del Verbo, Estudios Valentinianos I/1, Romae, 1958. 
- Órdenes Morales, Mauricio. "La teología del Verbo según Santo Tomás en la Suma Contra Gentiles", en E. GÓMEZ (Ed), La persona: divina, angélica, humana. Actas del primer Congreso Internacional de filosofía tomista, Santiago, CET, 2014, 245-255.

- - "Conocimiento y verdad según Tomás de Aquino", Revista Chilena de Estudios Medievales", 14, 2018, 52-63.

- Rovira Belloso, Josè María. "Teología del Padre", Scripta Theologica 20, 1998, 2/3, 491-522.

- Tomar Romero, Francisca. "La memoria como <autoconocimiento> y <amor de sí>> , Revista española de filosofía medieval, 8, 2001, 95-110.

- Schell, Patricia. "La doctrina de la memoria espiritual en el De Veritate", comunicación al Congresso Tomista Internazionale, Roma 2003,

- - "La doctrina tomista de la memoria espiritual. Un punto de equilibrio ante las anomalías de la psicología contemporánea", Sapientia, LIX, 2004, 49-75. 